\title{
Inactivation of p38 MAPK contributes to stem cell-like properties of non-small cell lung cancer
}

\author{
Yan Fang ${ }^{1}$, Juan Wang ${ }^{1}$, Guanwen Wang ${ }^{1}$, Chen Zhou ${ }^{1}$, Peng Wang ${ }^{1}$, Shuangtao \\ Zhao $^{1}$, Shaorong Zhao ${ }^{1}$, Shan Huang ${ }^{2}$, Weijun Su ${ }^{1,2}$, Pengling Jiang ${ }^{3}$, Antao Chang ${ }^{1,2}$, \\ Rong Xiang ${ }^{1}$, Peiqing Sun ${ }^{1,2}$ \\ ${ }^{1}$ Department of Immunology, School of Medicine, Nankai University, Tianjin, China \\ ${ }^{2}$ Department of Cancer Biology and Comprehensive Cancer Center, Wake Forest University Medical Center, Winston-Salem, \\ North Carolina, USA \\ ${ }^{3}$ Key Laboratory of Cancer and Key Laboratory of Breast Cancer Prevention and Therapy, Tianjin Medical University Cancer \\ Institute and Hospital, Tianjin Medical University, Tianjin, China \\ Correspondence to: Peiqing Sun, email: psun@wakehealth.edu \\ Rong Xiang, email: rxiang@nankai.edu.cn
}

Keywords: p38, Hsp27, MK2, stemness markers, lung cancer stem cells

Received: November 15, $2016 \quad$ Accepted: February 15, $2017 \quad$ Published: March 01, 2017

Copyright: Fang et al. This is an open-access article distributed under the terms of the Creative Commons Attribution License (CC-BY), which permits unrestricted use, distribution, and reproduction in any medium, provided the original author and source are credited.

\section{ABSTRACT}

Cancer stem cells (CSCs) are recognized as the major source for cancer initiation and recurrence. Yet, the mechanism by which the cancer stem cell properties are acquired and maintained in a cancer cell population is not well understood. In the current study, we observed that the level of active p38 MAPK is downregulated, while the level of the stemness marker SOX2 is upregulated in lung cancer tissues as compared to normal tissues. We further demonstrated that inactivation of p38 is a potential mechanism contributing to acquisition and maintenance of cancer stem cell properties in non-small cell lung cancer (NSCLC) cells. p38, in particular the p38y and p38ס isoforms, suppresses the cancer stem cell properties and tumor initiating ability of NSCLC cells by promoting the ubiquitylation and degradation of stemness proteins such as SOX2, Oct4, Nanog, KIf4 and c-Myc, through MK2-mediated phosphorylation of Hsp27 that is an essential component of the proteasomal degradation machinery. In contrast, inactivation of p38 in lung cancer cells leads to upregulation of the stemness proteins, thus promoting the cancer stem cell properties of these cells. These findings have demonstrated a novel mechanism by which cancer stem cell properties are acquired and maintained in a cancer cell population, and have revealed a new function of the p38 pathway in suppressing cancer development. These studies have also identified a new pathway that can potentially serve as a target for cancer therapies aimed at eliminating CSCs.

\section{INTRODUCTION}

Lung cancer is one of the major causes of cancerdeath in the world [1]. Lung cancer can be classified into small cell lung carcinoma and non-small cell lung carcinoma (NSCLC) [2]. More than $85 \%$ of lung cancer is the NSCLC, which has lower survival rate [3]. It is thus of great interest to study the mechanisms underlying the development of lung cancer, especially that of NSCLC.

Cancer stem cells (CSCs) are a small population of cancer cells that possess capabilities of self-renewal, differentiation, and tumor initiation in vivo [4]. CSCs are the major source of cancer initiation, tumor relapse, and drug resistance, and play an important role in cancer development [4]. Overexpression of Oct4 (Octamer-binding transcription factor 4), SOX2 (SRY (sex determining region Y)-box 2), Nanog, Klf4 (Kruppel-like factor 4) and c-Myc, can induce somatic cells to acquire pluripotency [5]. These proteins also serve as the CSCs markers [6-8]. In particular, SOX2 interacts with Oct4 to maintain the pluripotency in embryonic stem cells (ESCs) [9]. SOX2 plays an essential role, not only in regulating pluripotency but also in mediating self-renewal and differentiation [9]. SOX2 expression is increased in several types of cancers, such as 
lung, breast, ovarian, prostate cancers [10-15]. However, the mechanisms by which SOX2 and other CSC markers are overexpressed in cancer are unknown. It also remains unclear how CSCs are acquired and how the stemness is maintained in a cancer cell population.

The p38 MAPK (mitogen-activated protein kinase) signaling pathway was initially identified as a mediator of inflammation and stress responses, but was later demonstrated to play important roles in different physiological or pathological conditions, including cancer development $[16,17]$. The role of p38 in cancer development seems to be context-dependent. While some studies reported that $\mathrm{p} 38$ promotes tumorigenesis by mediating tumor cell invasion and metastasis [18], others have shown that the p38 pathway functions as a tumor suppressor by inhibiting cell proliferation and mediating oncogene-induced senescence [17, 19]. However, the detailed mechanisms for the tumor suppressing activity of p38 have not been completely understood. The connection between p38 and CSCs has not been well studies.

Four isoforms of p38 MAPK have been identified in

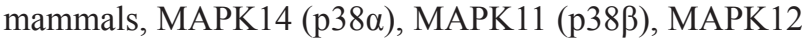

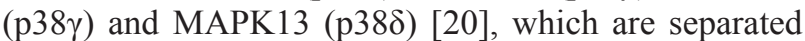
into two sub-groups: $\mathrm{p} 38 \alpha$ and $\mathrm{p} 38 \beta$, and $\mathrm{p} 38 \gamma$ and $\mathrm{p} 38 \delta$ [21]. MKK6 can phosphorylates the all p38 MAPK family members, while MKK3 mainly activates p38 $\alpha$, p38 $\gamma$ and p38 [16]. While p38 $\alpha$ is the best characterized isoform, the roles of $\mathrm{p} 38 \gamma$ and $\mathrm{p} 38 \delta$ in cancer have received increasing attention in recent years [22]. For example, it has been reported that $\mathrm{p} 38 \gamma$ and $\mathrm{p} 38 \delta^{-}$suppress cells migration, that $\mathrm{p} 38 \delta$ mediates contact inhibition, and that p38 inhibits cell proliferation [23, 24]. In addition, p38 $\gamma$ and $\mathrm{p} 38 \delta$ are essential for oncogene-induced senescence, which is a tumor suppressing mechanism [25, 26]. These findings indicate that $\mathrm{p} 38 \gamma$ and $\mathrm{p} 38 \delta$ have a tumor suppressing function. Consistent with this notion, the current study demonstrates that $\mathrm{p} 38 \gamma$ and $\mathrm{p} 38 \delta$ suppress the stemness by inhibiting the expression of stemness proteins in lung cancer cells.

Heat shock proteins (HSPs) are a protein family that act as molecular chaperons, which contains Hsp90, Hsp70, Hsp60, Hsp40 and Hsp27 [27]. Hsp27 has been reported to facilitate the refolding of damaged proteins [28]. More and more reports show that Hsp27 plays an important role in cancer, acting as either a tumor promoter or tumor suppressor in a context-dependent manner [29, 30]. For instance, inhibition of Hsp27 accelerated EMT, which was mediated by TGF- $\beta 1$, in lung cancer cells, suggesting that Hsp27 suppresses cancer development [29]. On the other hand, Hsp27 expression strongly correlated with poor survival and with non-clear margins of resection in patients with rectal tumors [30]. In addition to the molecular chaperon function, Hsp27 has also been reported to participate in a proteasomal complex to promote ubiquitylation and proteasomal degradation of multiple proteins under stress conditions [31-33]. Moreover, Hsp27 is a well-established downstream effector of $\mathrm{p} 38$. Upon activation by $\mathrm{p} 38$, the p38 downstream protein kinases MK2 and PRAK phosphorylate Hsp27 at Ser15, Ser78 and Ser82, thereby regulating the activity of Hsp27 [34, 35].

In the current study, we investigate the role of the p38 pathway in regulating the stemness properties of lung cancer cells. We observed that the level of active p38 is downregulated, while the level of the stemness marker SOX2 is upregulated in lung cancer tissues as compared to normal tissues. Further investigation reveals that p38, in particular the $\mathrm{p} 38 \gamma$ and $\mathrm{p} 38 \delta$ isoforms, suppresses the cancer stem cell properties of NSCLC cells by promoting the ubiquitylation and degradation of stemness proteins through MK2-dependent phosphorylation of Hsp27 that is an essential component of the proteasomal degradation machinery. These findings have demonstrated a novel mechanism by which cancer stem cell properties are acquired and maintained in a cancer cell population, and have revealed a new function of the p38 pathway in suppressing cancer development. These studies have also identified a new pathway that can potentially serve as a target for cancer therapies aimed at eliminating CSCs.

\section{RESULTS}

\section{The level of activated p38 is downregulated while the level of SOX2 is upregulated in lung cancer}

Previous studies have demonstrated that inactivation of p38 or p38 downstream signaling components promotes cancer development in mouse models [36-38], suggesting a tumor suppressing function of this pathway. To investigated the role of activated p38 (p-p38) in human cancer development, we analyzed the level of phosphorylated and activated p38 in human lung tumor samples using a tissue array containing 153 intact NSCLC tumor tissues (79 squamous cell carcinoma and 74 adenocarcinoma) and 31 intact normal lung tissues/ normal adjacent lung tissue (NAT) (18 normal lung tissue and 13 NAT). We observed that the level of p-p38 was significantly downregulated in lung cancer tissues as compared to normal tissues (Figure 1A), consistent with a tumor suppressing function of activated p38 in human cancer. Interestingly, the expression level of SOX2, a stemness marker in cancer cells was upregulated in tumor tissues as compared to the normal tissues (Figure 1A). We also perform the Spearman's rank correlation test, and found a weak negative correlation between SOX2 levels and p-p38 levels, with a $p$ value of 0.128 . These observations raise a possibility that active p38 may inhibit the expression of stemness proteins such as SOX2, and that inactivation of p38 in lung cancer cells leads to increased expression of SOX2, thus promoting the acquisition of cancer stem cell-like properties. 


\section{The $\mathrm{p} 38$ signaling pathway downregulates the expression of stemness markers and stem cell- like properties in non-small cell lung cancer cells}

To investigate the role of p38 in the stemness properties of lung cancer cells, we compared the levels of activated and phosphorylated p38 (p-p38) and SOX2 in 3 non-small cell lung cancer cell lines, A549, H460 and H1299. Indeed, there is a negative correlation between the p38 activity and the expression levels of SOX2. Among these 3 cell lines, A549 cells had the lowest level of p-p38 but the highest level of SOX2, while H1299 cells had the highest level of p-p38 but the lowest level of SOX2 (Figure 1B). H460 cells displayed intermediate levels of p-p38 and SOX2. These observations suggest that p38 may downregulate the expression of SOX2.

We further investigated the effects of constitutive activation or dominant negative inhibition of p38 on the expression of SOX2 and other stemness markers in these lung cancer cells. MKK3 and MKK6 are upstream activating kinases of $\mathrm{p} 38$. We overexpressed constitutively active mutants of MKK3 (MKK3E) and MKK6 (MKK6E) in A549 cells with the lowest p-p38 level, dominant negative mutants of MKK3 (MKK3A) and MKK6(MKK6A) in H1299 cells with the highest p-p38 level, and either constitutively active or dominant negative mutants of MKK3 and MKK6 in H460 cells with intermediate p-p38 level. The results showed that when p38 was constitutively activated by MKK3E and MKK6E (as indicated by increased p-p38 levels), the expression level of stemness markers, including SOX2, Oct4, Nanog, Klf4 and c-Myc, was decreased in A549 and H460 cells. On the contrary, when p38 activity was inhibited by the dominant negative MKK3A and MKK6A mutants (as indicated by decreased p-p38 levels), the expression level of those stemness markers were increased in H1299 and H460 cells (Figure 1C). The H1299-MKK3A cell line we constructed failed to express a detectable level of MKK3A for unknown reasons, and therefore, this cell line was excluded from further studies although it did express increased levels of at least some of the stemness proteins (Oct4, Nanog, Klf4 and c-Myc) as compared to the control cells (Figure 1C).

We next analyzed the effect of p38 activation and inhibition on the stem cell properties of the lung cancer cells, including percentage of side population and ability to form spheres. A side population that shows higher efflux of DNA-binding dye Hoechst 33342, as determined by flow cytometry, was firstly reported in murine bone marrow, which is enriched with hematopoietic stem cells (HSCs) [39]. To some extent, the tumor cells with high side population characteristics represents cancer stem cells [40-44]. We found that constitutive activation of $\mathrm{p} 38$ by MKK3E or MKK6E reduced the percentage of the side population in A549 and $\mathrm{H} 460$ cells, as compared to the cells transduced with a vector control (BP) (Figure 2A). In contrast, inhibition of $\mathrm{p} 38$ by MKK3A or MKK6 A in H460 and H1299 cells led to increases in the percentage of the side population in comparison with the vector control $(\mathrm{BH})$ (Figure 2A). Consistent with these observations,
A
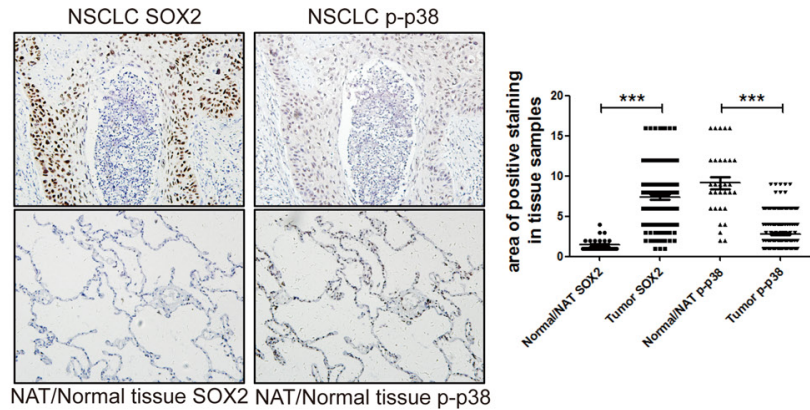

C

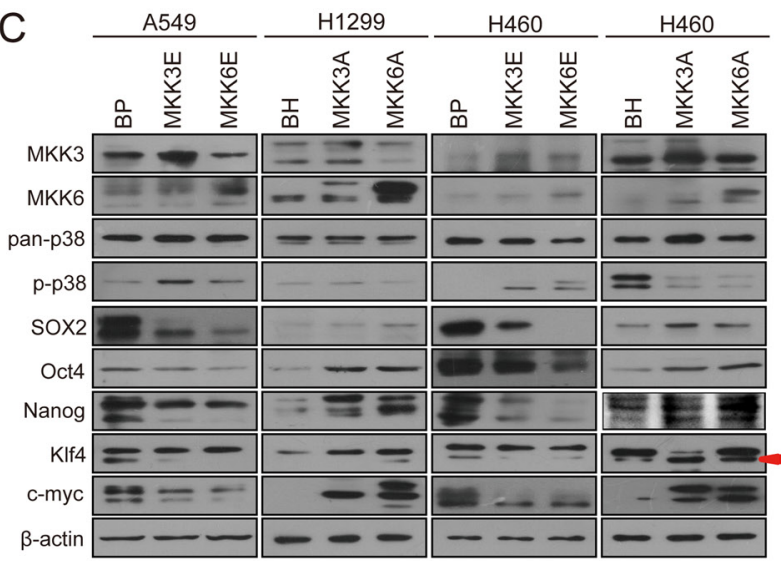

Figure 1: Activated p38 negatively regulates the expression of stemness proteins in non-small cell lung cancer (NSCLC). (A) IHC staining of SOX2 and p-p38 in serial sections of a human lung cancer tissue array containing 153 intact NSCLC tissues and 31 NAT/normal lung tissues. The scatter diagram shows quantification of area of positive staining for SOX2 and p-p38 in normal and tumor tissues, which is calculated by multiplying staining area (scored as $1,2,3$, and $4,1: 0-25 \%, 2: 25 \%-50 \%, 3: 50 \%-75 \%, 4: 75 \%-100 \%$, of positive tissue area) with staining intensity (scored as $1,2,3$, and 4 based on color). $* * *$ indicates significant difference with $P<0.001$ vs normal tissues in Mann-Whitney test. (B) Negative correlation between the expression levels of p-p38 and SOX2 in three non-small cell lung cancer (NSCLC) cell lines, as detected by Western blot analysis. (C) Western blot analysis of A549 and H460 cells transduced with constitutively active MKK3 or MKK6 (MKK3E/6E) or vector control (BabePuro, BP) or H460 and H1299 cells transduced with dominant negative MKK3 or MKK6 (MKK3A/6A) or vector control (BabeHygro, BH), showing that p38 activation leads to downregulation, while p38 inhibition leads to upregulation, of stemness protein expression. Arrow indicates the Klf4 band. 
in the sphere formation assay, MKK3E and MKK6E decreased the number as well as the size of spheres formed by A549 and H460 cells, while MKK3A and MKK6A increased the ability to form spheres in H460 and H1299 cells, in comparison with their respective vector controls (Figure 2B). These results demonstrate that activated $\mathrm{p} 38$ suppresses the stem cell-like properties of NSCLC cells, and that inactivation of $\mathrm{p} 38$ leads to expansion of cancer stem cells.

\section{p38 $\gamma$ and p38 $\delta$ suppress the stemness of NSCLC cells}

The observations described above indicate that p38 MAPK suppresses the stemness of NSCLC cells. Four p38 MAPK isoforms, p38 $\alpha, \mathrm{p} 38 \beta, \mathrm{p} 38 \gamma, \mathrm{p} 38 \delta$, have been identified in mammals $[22,45]$. These p38MAPK isoforms are divided into two sub-groups based on sequence homology and sensitivity to chemical inhibitors, with one sub-group including $\mathrm{p} 38 \alpha$ and $\mathrm{p} 38 \beta$ and the other including $\mathrm{p} 38 \gamma$ and $\mathrm{p} 38 \delta$. These four isoforms plays different roles in the progress of tumor development $[18,46,47]$. To determine which isoforms may play a role in regulation of stemness of NSCLC cells, we employed a 2-fold strategy, by either stably expressing wild type or constitutively active mutant of each p38 isoform in A549 and H460 cells, or by knocking down each p38 isoform using isoform-specific shRNA in H460 and H1299 cells [25, 26], followed by measurement of the expression levels of the stemness markers, the percentage of side population and the ability of the cells to form spheres.

Western blot analysis confirmed that the p38 isoforms were either overexpressed or knocked down by shRNA in appropriate cell lines (Supplementary Figure 1), and that the constitutively active mutants of p38 isoforms displayed increased autophosphorylation levels as compared to their wild type counterparts and the vector control (Figure 3A). Expression of the constitutive active $\mathrm{p} 38 \gamma$ and $\mathrm{p} 38 \delta$, and sometimes that of the wild type forms of these 2 isoforms, suppressed the expression of SOX2, Oct4, Nanog, Klf4 and c-Myc in A549 and H460 cells, while neither the wild type forms nor the active mutants of $\mathrm{p} 38 \alpha$ and $\mathrm{p} 38 \beta$ had any inhibitory effect on the expression of these stemness markers (Figure 3A). In addition, knockdown of $\mathrm{p} 38 \gamma$ and $\mathrm{p} 38 \delta$, but not that of $\mathrm{p} 38 \alpha$ and $\mathrm{p} 38 \beta$, increased the expression of SOX 2 , Oct4, Nanog, Klf4 and c-Myc in H460 and H1299 cells (Figure 3A). Furthermore, consistent with the ability of p38 $\gamma$ and $\mathrm{p} 38 \delta$ to regulate the stemness marker expression, ectopic expression of wild type or constitutively active mutants of $\mathrm{p} 38 \gamma$ and $\mathrm{p} 38 \delta$ reduced the percentage of the side population in A549 and H460 cells (Figure 3B, Supplementary Figure 2), while shRNA-mediated knockdown of p38 $\gamma$ and $\mathrm{p} 38 \delta$ increased the percentage of the side population in H460 and H1299 cells (Figure 3B, Supplementary Figure 3). In contrast, ectopic expression of wild type or constitutive active mutants of $\mathrm{p} 38 \alpha$ or $\mathrm{p} 38 \beta$, and knockdown of $\mathrm{p} 38 \alpha$ and $\mathrm{p} 38 \beta$, had no effect on the percentage of the side population in these lung cancer cells
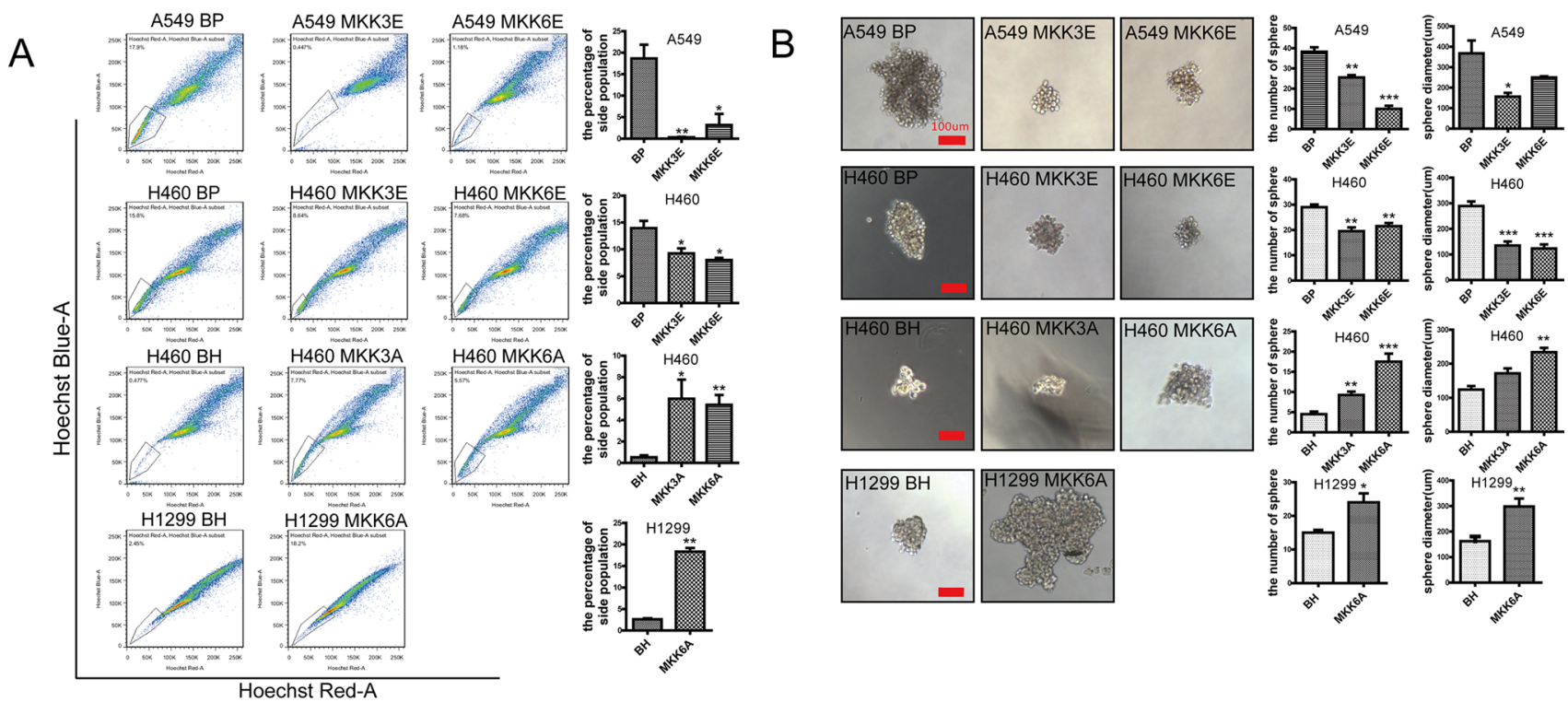

Figure 2: Activated p38 downregulates the stem cell properties of NSCLC cells. (A) Flow cytometry showing the percentage of the side population detected by Hoechst33342 staining in A549 and H460 cells transduced with vector control (BP), MKK3E or MKK6E and H460 and H1299 cells transduced with vector control (BH), MKK3A or MKK6A. Bar graphs show quantification of the percentage of side population. (B) Sphere formation assay of A549 and H460 cells transduced with vector control (BP), MKK3E or MKK6E and H460 and H1299 cells transduced with vector control (BH), MKK3A or MKK6A. Scar bar, $100 \mu$ m. Bar graphs show quantifications of the number and diameter of the spheres, respectively. * indicates $P<0.05$, ** indicates $P<0.01$, and *** indicates $P<0.001$ vs BP or BH control in Student's $t$-test. 
(Figure 3B, Supplementary Figures 2, 3). These results indicate that $\mathrm{p} 38 \gamma$ and $\mathrm{p} 38 \delta$ are the main $\mathrm{p} 38$ isoforms that inhibit the stemness properties of the NSCLC cells.

\section{Constitutively activated p38 $\gamma$ and $\mathrm{p38} \delta$ decrease the tumor initiating ability of A549 cells in vivo}

Cancer stem cells are regarded as tumor initiating cells. Suppression of cancer stemness by activated p38 prompted us to investigate the effect of $\mathrm{p} 38$ on the tumor initiating ability of NSCLC cells. We injected varying amounts of control A549 cells (A549-BP) or A549 cells expressing constitutively active mutants of p38 $\gamma$ (A549-

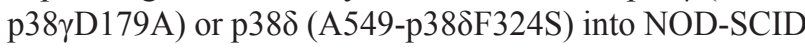
mice and monitored tumor formation and growth. The results showed that the minimal amount of cells needed for tumor formation in vivo was $1 \times 10^{5}$ for A549-BP cells,

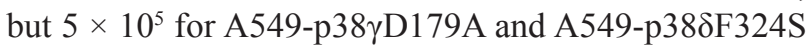
cells (Figure 3C, Supplementary Figure 4). Moreover, the A549-p38 $\mathrm{D} 179 \mathrm{~A}$ and A549-p388F324S tumors also grew at a reduced rate as compared to the A549-BP tumors (Figure 3D, 3E). These results indicated that constitutive activation of $\mathrm{p} 38 \gamma$ and $\mathrm{p} 38 \delta$ decreases the tumor initiating ability of NSCLC in vivo.

\section{p38 $\gamma$ and $\mathbf{p 3 8 \delta}$ reduce the protein stability of the stemness markers}

The role of p38 in regulating the stemness of lung cancer cells prompted us to investigate the mechanism by which $\mathrm{p} 38$ suppresses the expression of the stemness proteins. We first examined the effect of p38 activation and inhibition on the mRNA levels of the stemness genes. We found that MKK3E and MKK6E failed to consistently suppress the mRNA levels of SOX2, Oct4, Nanog, Klf4 and m-Myc in A549 (Figure 4A) and H460 cells (Supplementary Figure 5A), and that MKK3A and MKK6A did not consistently increase the mRNA levels of these stemness genes in H460 (Supplementary Figure 5A) and H1299 cells (Figure 4A), suggesting that regulation of these stemness genes by p38 does not occur at the transcriptional or post-transcriptional level. We observed some modest ( $\leq 2$-fold), although significant, differences in mRNA levels of stemness proteins in cells with activated or inactivated p38 as compared to the control cells. However, these differences are inconsistent between different p38 activators (MKK3E and MKK6E) or inhibitors (MKK3A and MKK6A), among different lung cancer cell lines (compare Figure 4A and Supplementary Figure 5A) or among different stemness proteins, and most of them are not reflected at the protein levels. Thus, we consider these modest differences at the mRNA levels biologically insignificant.

We next investigated whether p38 could regulate the protein stability of the stemness genes. To explore this possibility, we measured the rate of protein degradation in NSCLC cells at $0,1,2,6,9$, and 15 hours after treatment with cycloheximide, a translation inhibitor. The results showed that the protein stability of SOX2, Oct4, Nanog, Klf4 and c-Myc was decreased when p38 was constitutively activated by MKK3E in A549 cells (Figure 4B, 4C), and was increased when p38 was inhibited by MKK3A in H460 cells (Supplementary Figure 5B) and by MKK6A in H1299 cells (Figure 4B). As a negative control, the status of p38 had not effect on the stability of the ERK protein (Figure 4B, 4C Supplementary Figure 5B). These observations suggest that activation of p 38 MAPK reduces protein stability of the stemness genes.

Using a similar approach, we next asked whether the protein stability of SOX2, Oct4, Nanog, Klf4 and c-Myc was regulated by $\mathrm{p} 38 \gamma$ and $\mathrm{p} 38 \delta$. We detected the half-life of these proteins in $\mathrm{H} 460$ cells expressing the wild type or constitutively active mutants of $\mathrm{p} 38 \gamma$ or $\mathrm{p} 38 \delta$, or shRNAs for these p38 isoforms. We found that that the active

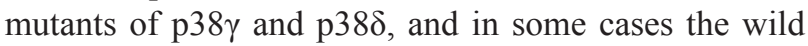
type forms of these p38 isoforms, decreased the protein stability of SOX2, Oct4, Nanog, Klf4 and c-Myc; and on the contrary, knockdown of $\mathrm{p} 38 \gamma$ and $\mathrm{p} 38 \delta$ increased the protein stability of these stemness markers (Figure 5). These results indicate that $\mathrm{p} 38 \gamma$ and $\mathrm{p} 38 \delta$ downregulates the stemness of NSCLC cells by reducing the protein stability of the genes that mediate stemness.

Of note, in addition to the constitutively active forms of $\mathrm{p} 38 \gamma$ and $\mathrm{p} 38 \delta$, wild type $\mathrm{p} 38 \gamma$ and $\mathrm{p} 38 \delta$ also reduced the percentage of side population (Figure 3B, Supplementary Figure 2) and decreased the expression levels (Figure 3A) and the protein stability (Figure 5) of some of the stemness genes, although to a less extent as compared to the constitutively active forms of $\mathrm{p} 38 \gamma$ and $\mathrm{p} 38 \delta$ in most cases. We reason that overexpression of wild type $\mathrm{p} 38$ isoforms may also lead to increases in the p38 activity in cells even though they do not carry constitutively active mutations, due to increases in the $\mathrm{p} 38$ protein concentrations. Indeed, the levels of p38 autophosphorylation were significantly increased in A549 and H460 cells expressing wild type $\mathrm{p} 38 \gamma$ and $\mathrm{p} 38 \delta$, as compared to cells transduced with vector control (Figure 3A). In addition, we measured the protein kinase activity of the wild type and constitutively active mutants of p38 $\gamma$ and $\mathrm{p} 38 \delta$ ectopically expressed in $\mathrm{H} 460$ cells using immunoprecipitation-protein kinase assays. We found that the wild type p38 $\gamma$ and $\mathrm{p} 38 \delta$ displayed significant protein kinase activities toward the ATF2 substrate, although the activities were not as high as the constitutively active mutants of these isoforms (Supplementary Figure 6). These observations suggest that the ability of p38 $\gamma$ and p38 to suppress the stemness of NSCLC cells depends on their protein kinase activities.

\section{p38 promotes ubiquitylation and proteasome- mediated degradation of SOX2}

Reduction in protein stability of the stemness genes by $\mathrm{p} 38$ raises a possibility that $\mathrm{p} 38$ may regulate ubiquitintargeted degradation of these proteins by proteasomes. 

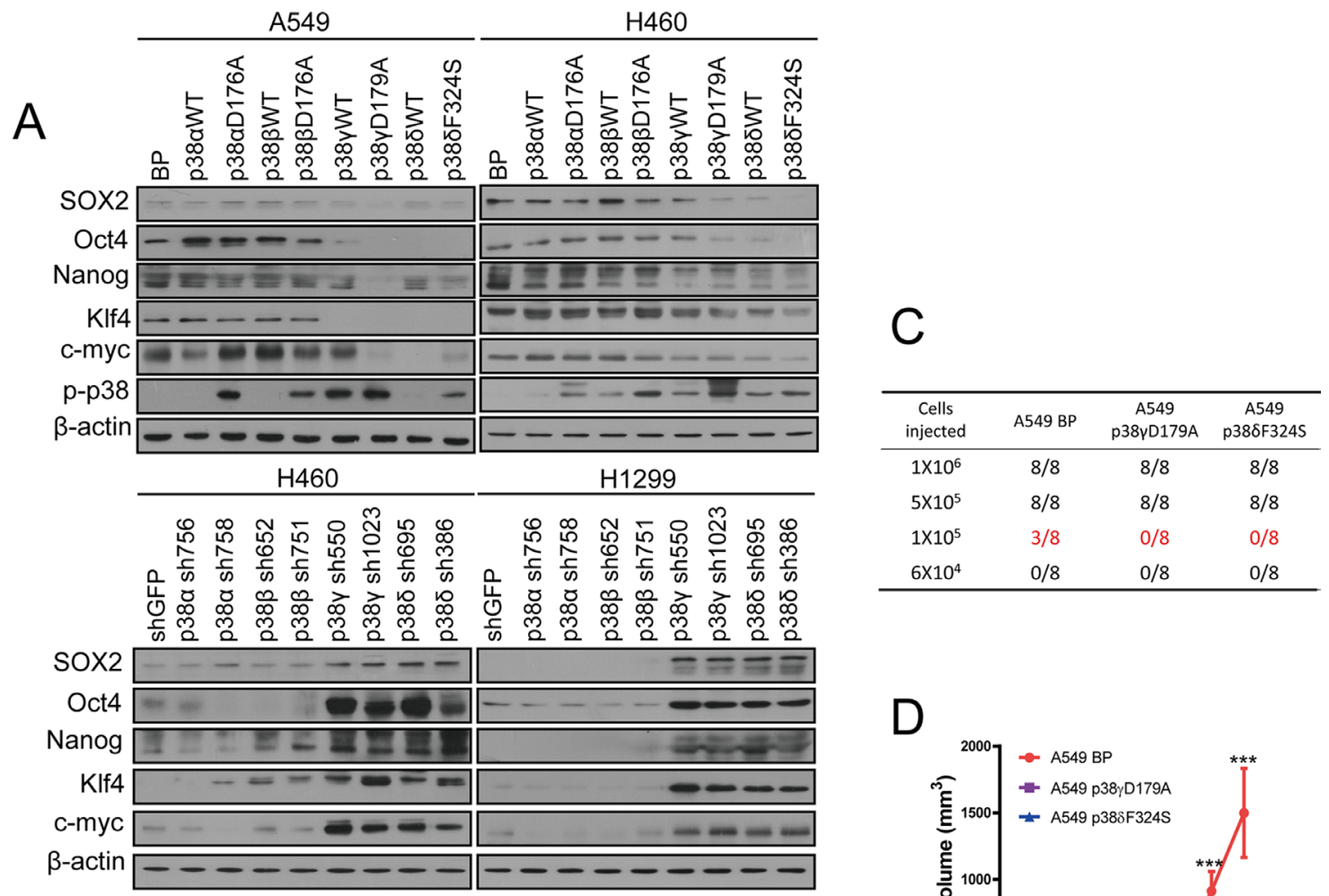

$\mathrm{B}$
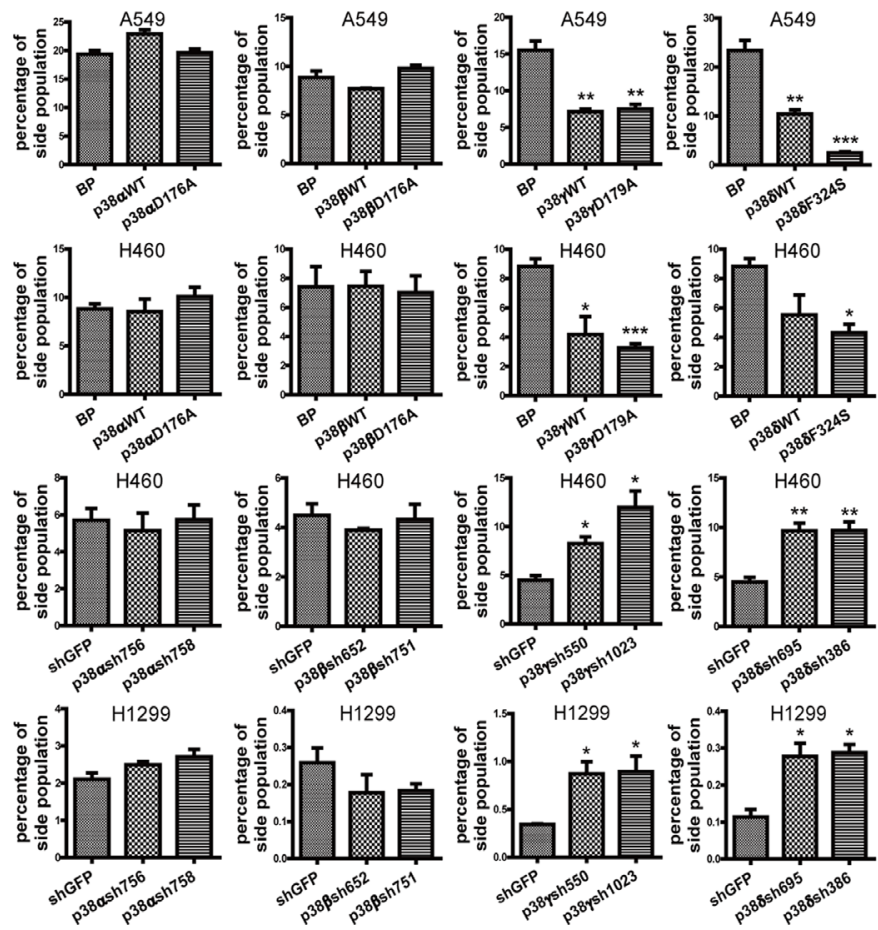

D

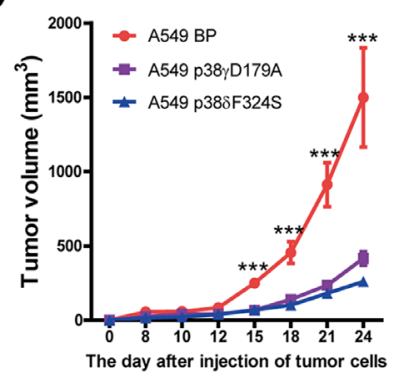

$E$

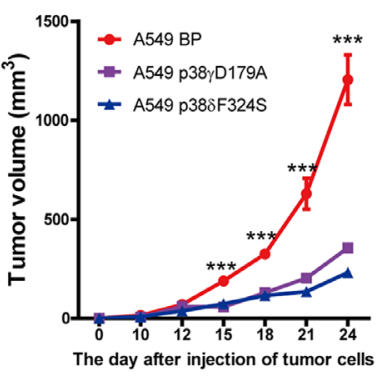

Figure 3: Activated p38 $\gamma$ and p38 $\delta$ suppress the stem cell properties of NSCLC cells. (A) Western blot analysis of the stemness markers in A549 and H460 cells transduced with vector control (BP), p38aWT, p38aD176A, p38bWT, p38ßD176A, p38gWT, p38yD179A, p38dWT, or p388F324S, and in H460 and H1299 cells transduced with shRNA for GFP or indicated p38 isoforms. (B) Quantification of percentage of the side population in A549 and H460 cells transduced with vector control (BP), p38aWT, p38 $\alpha$ D176A,

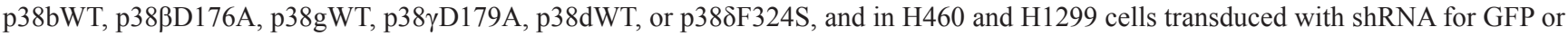
indicated p38 isoforms, as determined by flow cytometry. (C) Limit dilution xenograft tumor formation assay, showing number of tumors

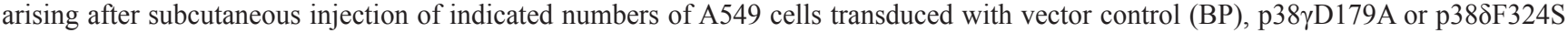
into 8 injection sites in Nod-scid mice. (D, E) The growth curves of xenograft tumors formed by $1 \times 10^{6}$ (D) or $5 \times 10^{5}$ (E) of A549 cells

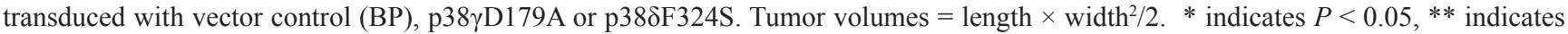
$P<0.01$, and $* * *$ indicates $P<0.001$ vs BP or shGFP control in Student's $t$-test. 
To investigate this possibility, we examined the effect of p38 activation on the ubiquitylation and degradation of one stemness protein, SOX2, in A549 and H1299 cells stably transduced with a HA-tagged SOX2, followed by transduction of MKK3E and MKK6A, respectively. Western blot analysis showed that HA-SOX2 was expressed properly in these cells (Figure 4D). As with the endogenous SOX2, the protein level of HA-SOX2 was reduced by MKK3E in A549 cells and increased by MKK6A in H1299 cells; however, the effects of MKK3E and MKK6A were essentially abolished by treatment with MG132, a proteasome inhibitor, as revealed by Western blot analysis (Figure 4E, HA-tag, IB), indicating that $\mathrm{SOX} 2$ is indeed degraded by proteasomes in the presence of activated p38. Furthermore, we immunoprecipitated HA-SOX2 using an antibody against HA and detected unbiquitylation of HA-SOX2 by Western blotting using an antibody against ubiquitin. The results showed that both in the presence and absence of MG132 treatment, the ubiquitylation of SOX2 was increased by MKK3E in A549 cells, and decreased by MKK6A in H1299 cells, in comparison to the cells transduced with vector controls (Figure 4E). Based on these observations, we conclude that activated p38 downregulates the protein stability of
SOX2 by promoting its ubiquitylation and proteasomemediated degradation.

\section{p38 regulates stemness of non-small-cell carcinoma through phosphorylation of Hsp27 at Ser78 and Ser82}

Hsp27 is a p38-regulated small heat shock protein that promotes protein ubiquitylation and proteasomemediated protein degradation. Activated p38 induces phosphorylation of Hsp27 at Ser15, Ser78 and Ser82, through p38 downstream substrate kinases MK2 and PRAK $[34,35]$. In response to stresses, Hsp27 binds to its protein targets such as I- $\kappa \mathrm{Ba}[31]$, p27 ${ }^{\mathrm{Kip} 1}$ [32], and AUF1 [33], and promotes their ubiquitylation and proteasomemediated degradation. This function of Hsp27 seems to depend on p38-mediated phosphorylation, because stresses that are known to activate the p38 pathway and the phosphomimetic mutations of Ser15, Ser78 and Ser82 of Hsp27 greatly enhanced the ability of Hsp27 to bind to and to promote the proteasomal degradation of the target proteins [31-33]. In addition, Hsp27 seems to mediate the proteasomal degradation of multiple proteins, as ectopic expression of Hsp27 decreased the overall level of
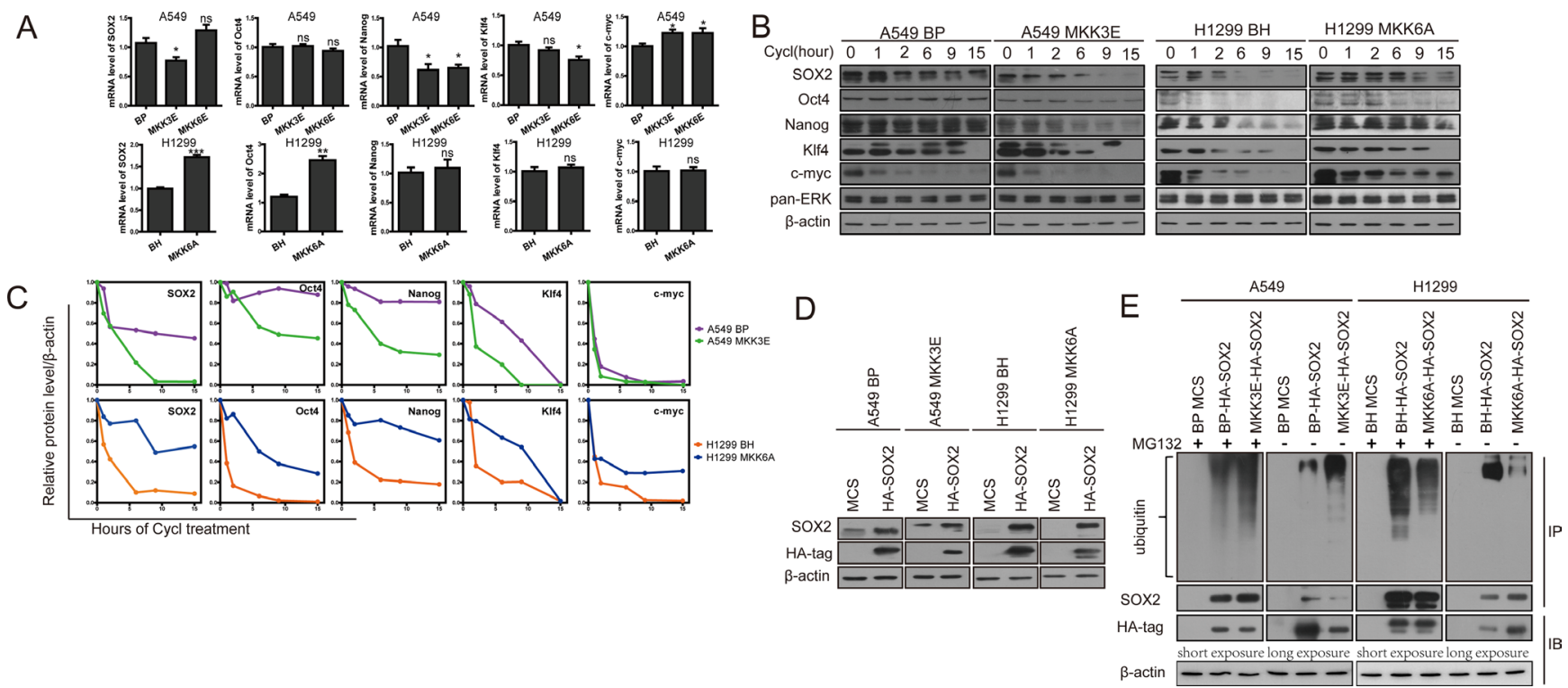

Figure 4: Activated p38 MAPK reduces protein stability of the stemness proteins and promotes ubiquitylation and proteasome-mediated degradation of SOX2. (A) Relative mRNA levels of the stemness proteins in A549 cells transduced with vector control (BP), MKK3E or MKK6E and H1299 cells transduced with vector control (BH) or MKK6A, as determined by quantitative real time PCR analysis. ns indicates no significant difference with $P>0.05, *$ indicates significant difference with $P<0.05$, ** indicates $P<0.01$, and $* * *$ indicates $P<0.001$ vs BP or BH control in Student's $t$-test. (B) Western blot analysis of the protein stability of the stemness proteins in A549 cells transduced with vector control (BP) or MKK3E and H1299 cells transduced with vector control (BH) or MKK6A after treated with cycloheximide for indicated time. The pan-ERK was as a negative control. (C) Quantification of the results in (B) using ImageJ. (D) Western blot analysis of A549 cells transduced with vector control (MCS) or HA-SOX2 and vector control (BP) or MKK3E, and H1299 cells transduced with vector control (MCS) or HA-SOX2 and vector control (BH) or MKK6A. (E) Western blot analysis of HA-SOX2 immunoprecipitated from A549 cells transduced with vector control (MCS) or HA-SOX2 and vector control (BP) or MKK3E and H1299 cells transduced with vector control (MCS) or HA-SOX2 and vector control (BH) or MKK6A, with (+) or without (-) treatment with MG132 (IP). Ubiquitylated SOX2 was detected by an anti-ubiquitin antibody, while total SOX2 was detected by an antiSOX2 antibody. Part of the lysate input (IB) was subjected to direct Western blotting using an anti-HA antibody. 
ubiquitylated proteins under stress conditions [31]. These observations led us to investigate whether Hsp27 mediates the proteasomal degradation of the stemness proteins in response to activated $\mathrm{p} 38$ in NSCLC cells.

We found that in A549 cells with low level of activated $\mathrm{p} 38$, phosphorylation of Hsp27 at Ser15, Ser78 and Ser82 was stimulated by ectopic expression of constitutively active forms of MKK3, MKK6, p38 $\gamma$ and $\mathrm{p} 38 \delta$, and to a less extent by wild type $\mathrm{p} 38 \gamma$ and $\mathrm{p} 38 \delta$ (Figure 6A). Conversely, in H1299 cells with high level of activated $\mathrm{p} 38$, expression of the dominant negative form of MKK6 (MKK6A) or knockdown of p38 $\gamma$ or p38 essentially abolished phosphorylation of Hsp27 on these 3 sites. Two p38 downstream substrate kinases MK2 and PRAK can directly phosphorylate Hsp27 at Ser15, Ser78 and Ser82 upon activation by p38 [34, 35]. To determine the role of MK2 and PRAK in Hsp27 phosphorylation in lung cancer cells, we knocked down MK2 and PRAK using shRNA in A549 cells. We found that the MK2 shRNA, but not the PRAK shRNA, greatly reduced Hsp27 phosphorylation at Ser78 and Ser82 induced by

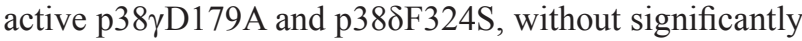
impacting phosphorylation of Ser15 (Figure 6B). These findings indicate that active $\mathrm{p} 38 \gamma$ and $\mathrm{p} 38 \delta$ induce Hsp27Ser78 and -Ser82 phosphorylation through MK2 in NSCLC cells.

To investigate the role of p38-induced Hsp27 phosphorylation in cancer cell stemness, we constructed Hsp27 mutant proteins containing phosphomimetic (S15D, S78D, S82D) or phosphorylation-resistant (S15A, S78A, S82A) mutations at Ser15, Ser78 and Ser82. In A549 cells with low level of p-p38 but high levels of stemness proteins, the phosphomimetic Hsp27-S78D/ S82D (Hsp27-DblD) and Hsp27-S15D/S78D/S82D (Hsp27-TriD), and to a less extent wild type Hsp27 and Hsp27-S15D, reduced the expression of SOX2, Oct4, Nanog, Klf4 and c-Myc (Figure 6C). In contrast, in A549 cells expressing constitutively active form of MKK3E, which activated p38 leading to reduced expression of the stemness proteins, the phosphorylation-resistant Hsp27S78A/S82A (Hsp27-DblA) and Hsp27-S15A/S78A/S82A (Hsp27-TriA) increased the expression of these stemness proteins (Figure 6C). Consistent with the effect of the Hsp27 mutants on the expression of the stemness proteins, Hsp27-DblD and -TriD reduced the percentage of the side population in A549 cells, while Hsp27-DblA and -TriA increased the percentage of the side population in A549MKK3E cells (Figure 6D, 6E). These data indicate that p38-induced phosphorylation of Hsp27, especially that at Ser78 and Ser82, enhances the ability of Hsp27 to reduce the expression of the stemness proteins and to suppress the stemness of NSCLC cells.

Due to the involvement of Hsp27 in the proteasomal complex [31-33], we further investigated the effect of these Hsp27 mutants on the stability of the stemness proteins. Indeed, the phosphomimetic Hsp27 mutant (Hsp27-TriD), and to a less extent the wild type Hsp27, reduced the half-life to the SOX2, Oct4, Nanog, Klf4 and c-Myc protein in A549 cells, while the phosphorylationresistant Hsp27 mutant (Hsp27-TriA) increased the halflife of these stemness proteins in A549-MKK3E cells (Figure 7A, 7B). Therefore, Hsp27 promotes degradation of the stemness proteins in a manner that depends on p38/MK2-mediated phosphorylation at Ser78 and Ser82. The phosphomimetic Hsp27 mutant displayed enhanced ability to promote stemness protein degradation, while the phosphorylation-resistant mutant of Hsp27 acted dominant negatively to inhibit degradation of these proteins in cells with activated $\mathrm{p} 38$.

It was shown that Hsp27 directly binds to the proteins that it targets for proteasome-mediated degradation [31-33]. We thus investigated whether Hsp27 directly interacts with the stemness proteins using immunoprecipitation-Western blot analysis. Hsp27 was

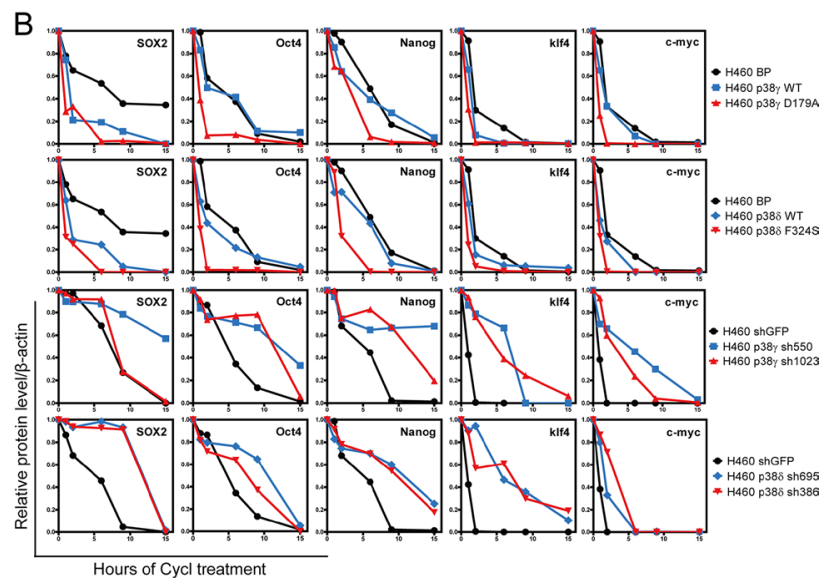

Figure 5: Activated p38 $\gamma$ and $\mathbf{p 3 8} \delta$ reduce the protein stability of the stemness proteins. (A) Western blot analysis of the

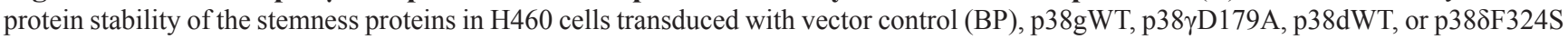
(upper panels), and in $\mathrm{H} 460$ cells transduced with shRNA for GFP, p38 $\gamma$ or p38 (lower panels), after treated with cycloheximide for indicated time. (B) Quantification of results in (A) using ImageJ. 
immunoprecipitated from A549 cells expressing wild type Hsp27 (A549-Hsp27-WT) or the phosphoomimetic Hsp27 (A549 BP-Hsp27-TriD) or control A549 cells (A549-MCS), and the presence of the stemness proteins in the immunoprecipitates were detected by Western blotting. The results show that SOX2, Oct4, Nanog, Klf4 and c-Myc indeed bind to wild type Hsp27, and that the interactions between Hsp27 and the stemness proteins are further enhanced by the phosphomimetic mutation on the MK2 phosphorylation sites, although the total levels of the stemness proteins were reduced in HSP27-TriD cells as compared to the HSP27-WT cells (Figure 7C). We

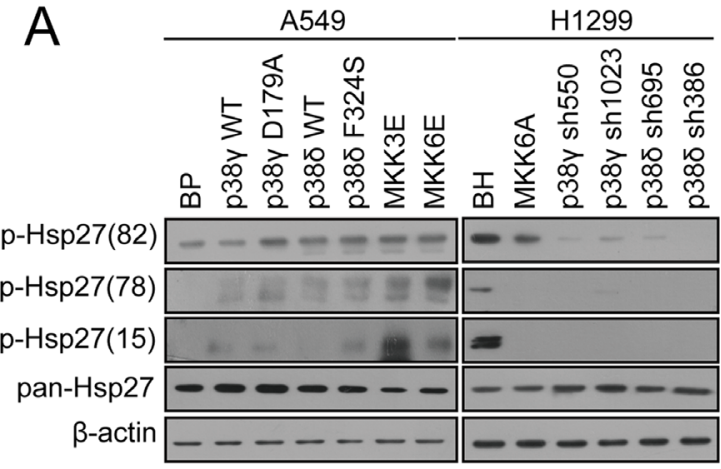

B
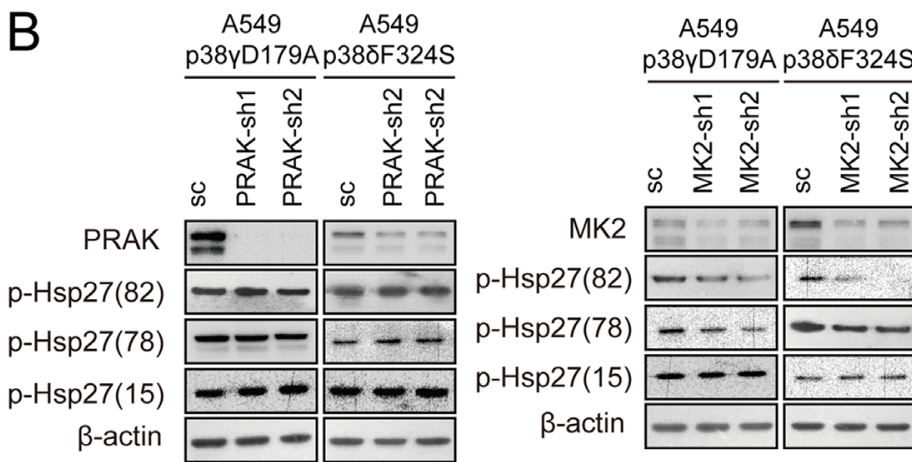

C
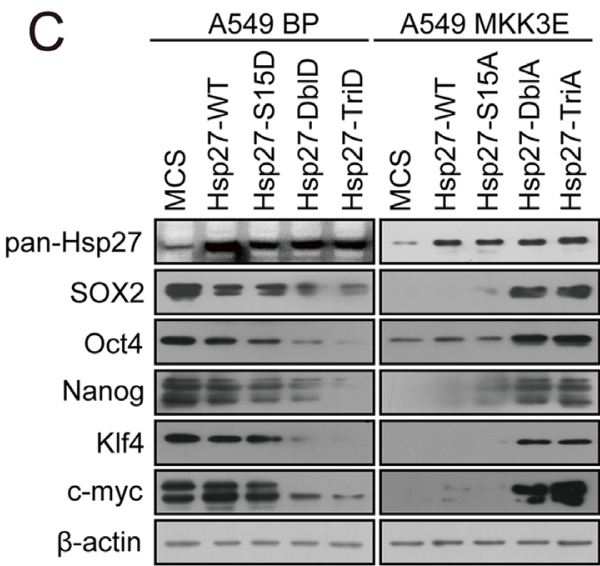

D

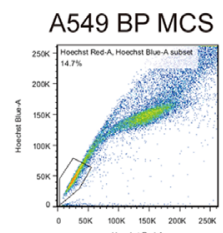

A549 BP Hsp27-WT
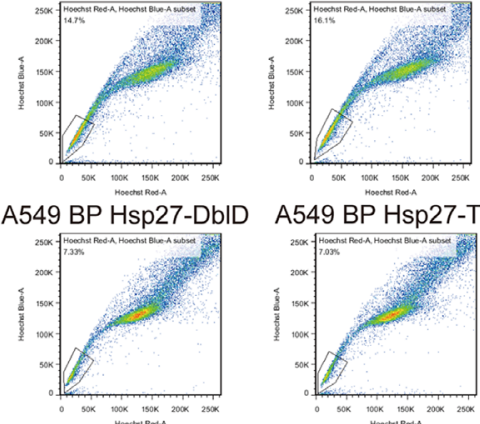

A549 BP Hsp27-TriD

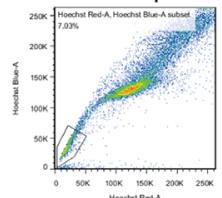

A549 MKK3E MCS A549 MKK3E Hsp27-WT
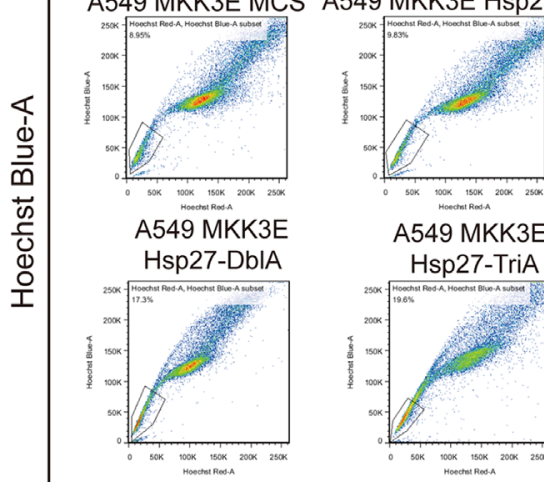

A549 MKK3E

Hsp27-TriA

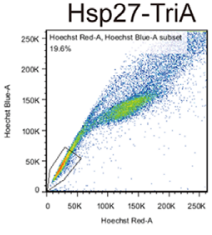

Hoechst Red-A
E

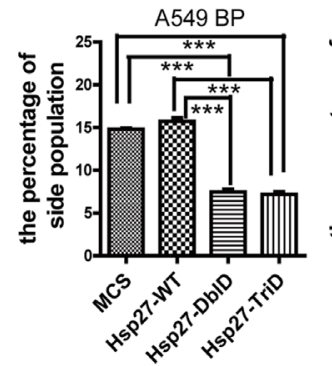

Figure 6: Activated p38 suppresses the stem cell-like properties of NSCLC cells through MK2-dependent phosphorylation of Hsp27 at Ser78 and Ser82. (A) Western blot analysis of Hsp27 phosphorylated at Ser15, Ser78 and Ser82 in A549 cells transduced with vector control (BP), p38gWT, p387D179A, p38dWT, p388F324S, MKK3E or MKK6E, and H1299 cells

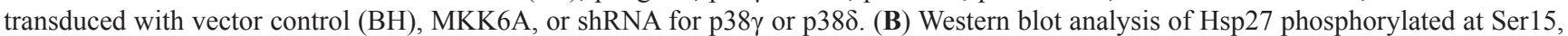

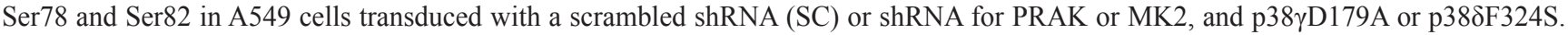
(C) Western blot analysis of the stemness proteins in A549 cells transduced with vector control (MCS), wild type Hsp27 (Hsp27-WT) or phosphomimetic mutants of Hsp27 (Hsp27-S15D, Hsp27-DblD, Hsp27-TriD) (left panels), and in A549 cells transduced with vector control (MCS), wild type Hsp27 (Hsp27-WT) or phosphorylation-resistant mutants of Hsp27 (Hsp27-S15A, Hsp27-DblA, Hsp27-TriA) and MKK3E (right panels). (D) Flow cytometry analysis was performed to determine the percentage of the side population in A549 cells transduced with vector control (MCS), wild type Hsp27 (Hsp27-WT) or phosphomimetic mutants of Hsp27 (Hsp27-DblD, Hsp27-TriD), and in A549 cells transduced with vector control (MCS), wild type Hsp27 (Hsp27-WT) or phosphorylation-resistant mutants of Hsp27 (Hsp27-DblA, Hsp27-TriA) and MKK3E. (E) Quantification of the results in (D). *** indicates significant difference with $P<0.001$ in Student's $t$-test. 
also performed the IP experiment in A549-MKK3E cells expressing HSP27-WT or HSP27-TriA, and the data show that although the total levels of the stemness proteins are increased in HSP27-TriA cells, their binding to HSP27 is reduced as compared to HSP27-WT cells (Figure 7D).

Taken together, these findings suggest that p38 inhibits the stemness properties of NSCLC cells by inducing the MK2-mediateed phosphorylation of Hsp27 at Ser78 and Ser82, which in turn enhances the binding to Hsp27 to the stemness proteins and promotes the proteasomal degradation of these stemness proteins.

\section{DISCUSSION}

The tumor suppressing role of several p38 pathway components has been demonstrated in mouse cancer models in vivo. Conditional deletion of $\mathrm{p} 38 \alpha$ in adult mice enhances both initiation and progression of K-RasG12Vinduced lung cancer [37] and accelerates chemicalinduced liver tumor development [38]. Deletion of the p38 downstream kinase PRAK also renders mice prone to skin papilloma induction by DMBA and accelerates lymphomagenesis in $\mathrm{E} \mu-\mathrm{N}-\mathrm{RasG} 12 \mathrm{D}$ transgenic mice $[36,48]$. However, whether the p38 pathway also has a tumor suppressing function during human cancer development has not been reported. By analyzing a tissue array containing 153 human lung cancer samples and 31 normal human lung tissues, we demonstrated that the level of activated, phosphorylated p38 is significantly downregulated in lung tumors as compared to normal tissues, thus supporting the notion that activated p38 suppresses human lung cancer development. The mechanism underlying the inactivation of p38 in lung cancer is currently under investigation. It has been reported that the p38 phosphatase Wip1 is frequently activated through amplification in human breast cancer $[49,50]$. Furthermore, Gstm1, a member of the glutathione S-transferase family that inhibit p38 activation by oxidative stress, is overexpressed in multiple types of cancers [51]. It will be interesting to determine whether Wip1 and Gstm1 are also overexpressed in lung tumor samples and contribute to inactivation of $\mathrm{p} 38$.

Although the p38 pathway has been implicated in tumor suppression, the mechanism underlying the tumor suppressing activity of p38 has not been well understood. Our observation that a stemness marker SOX2 was upregulated in lung cancer tissues concurrently with the reduced level of activated p38, prompted us to investigate a possibility that p38 may inhibit stemness by downregulating the stemness proteins in lung cancer cells. Indeed, we observed that the level of activated p38 negatively correlated with the level of SOX2 in NSCLC cells, and that constitutive activation of p38 in cells with low level of p-p38 reduced the expression

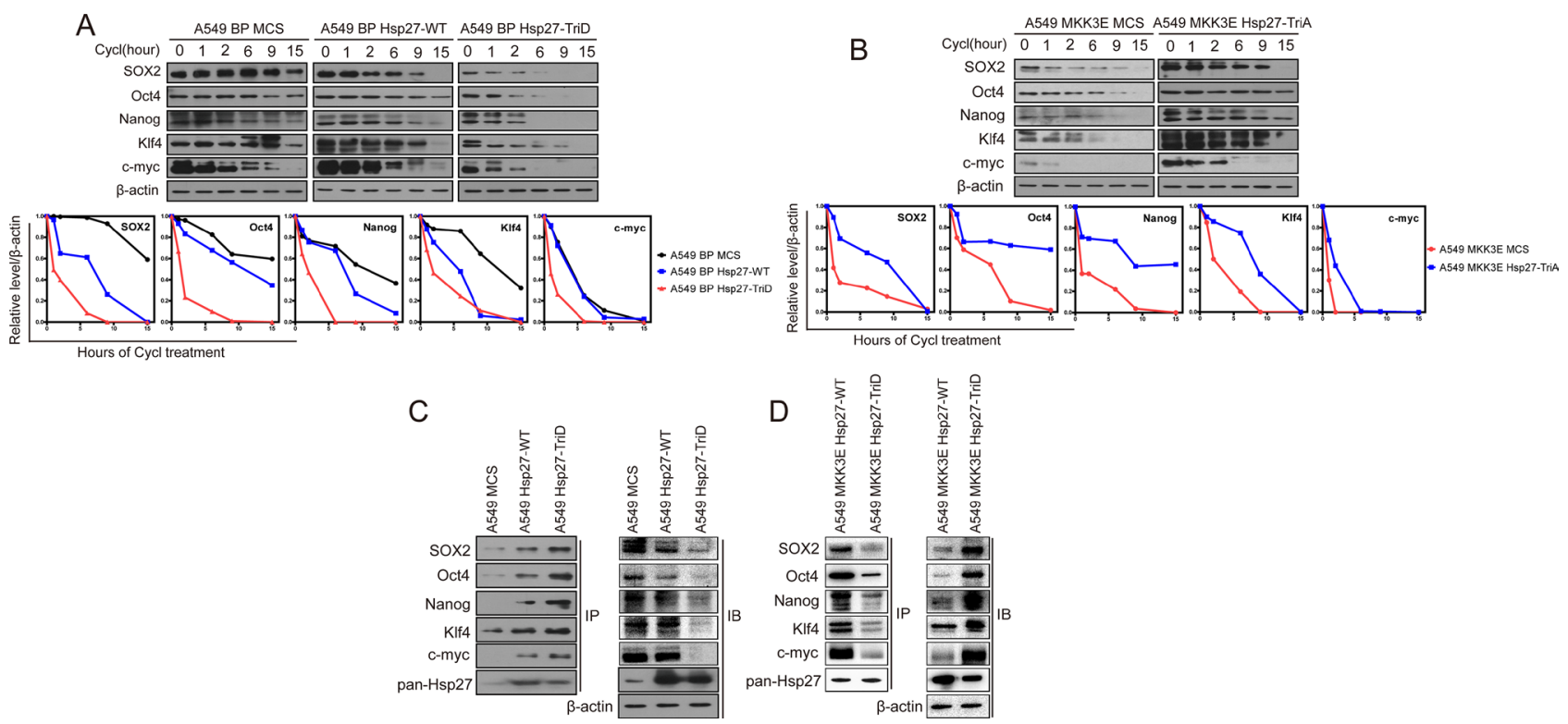

Figure 7: p38 $\gamma$ and $\mathbf{p 3 8 \delta}$ regulate the protein stability of the stemness proteins through phosphorylation of Hsp27, which enhances the interaction between Hsp27 and the stemness proteins, in NSCLC cells. (A, B) Western blot analysis of the protein stability of the stemness proteins in A549 cells transduced with vector control (MCS), wild type Hsp27 (Hsp27-WT) or phosphomimetic mutants of Hsp27 (Hsp27-TriD) (A), and in A549 cells transduced with vector control (MCS) or phosphorylation-resistant mutants of Hsp27 (Hsp27-TriA) and MKK3E (B), after treated with cycloheximide for indicated time. The bottom plots show quantification of the Western blotting results using ImageJ. (C) Western blot analysis of the stemness proteins present in Hsp27 immunoprecipitates from A549 cells transduced with vector control (MCS), wild type Hsp27 (Hsp27-WT) or phosphomimetic mutant of Hsp27 (Hsp27-TriD) (IP). Part of the lysate input was subjected to direct Western blotting (IB). (D) Western blot analysis of the stemness proteins present in Hsp27 immunoprecipitates from A549 cells transduced with MKK3E and vector control (MCS), wild type Hsp27 (Hsp27-WT) or unphosphorylatable mutant of Hsp27 (Hsp27-TriA) (IP). Part of the lysate input was subjected to direct Western blotting (IB). 
of SOX2 and other stemness proteins, the percentage of the side population and the ability to form spheres, while dominant negative inhibition of p38 in cells with high p-p38 level increased the expression of stemness proteins, the percentage of the side population and the sphere forming ability. We found that these effects of p38 on cancer cell stemness are mediated by the p38 $\gamma$ and $\mathrm{p} 38 \delta$ isoforms, but not the $\mathrm{p} 38 \alpha$ and $\mathrm{p} 38 \beta$ isoforms. There findings provide a novel mechanism underlying the tumor suppressing activity of p38, suggesting that p38, p38 $\gamma$ and p38 $\delta$ in this case, suppresses the cancer stem cell properties that contribute to many aspects of tumorigenesis, and that when p38 is inactivated, the cancer cell population gains stronger stemness properties leading to enhanced tumorigenic phenotypes. Consistent with a role of activated p38 in suppressing tumorigenesis by inhibiting the cancer stem cell properties, constitutively active forms of $\mathrm{p} 38 \gamma$ and $\mathrm{p} 38 \delta$ reduced the tumor initiating ability and tumor growth rate of NSCLC cells in vivo in a xenograft model.

Further investigation into the mechanism by which p38 regulates the expression of stemness proteins revealed that $\mathrm{p} 38 \gamma$ and $\mathrm{p} 38 \delta$ promote proteasomal degradation of these stemness proteins, through MK2-mediated phosphorylation of a downstream small heat shock protein Hsp27. Constitutively active MKK3, MKK6, p38 $\gamma$ and p38 induced phosphorylation of Hsp27 at Ser78 and Ser82 in a MK2-dependent manner in NSCLC cells with low p38 activity, while dominant negative MKK6A mutant and knockdown of p38 $\gamma$ and $\mathrm{p} 38 \delta$ in cells with high p38 activity abrogated phosphorylation of Hsp27 on these sites. Moreover, Hsp27 with phosphomimetic mutations on the MK2 phosphorylation sites displayed increased ability to promote stemness protein degradation and reduce the percentage of the side population, while the phosphorylation-resistant mutant of Hsp27 acted dominant negatively to inhibit degradation of these proteins and increase the percentage of the side population in cells with activated $\mathrm{p} 38$. These results indicate that Hsp27 acts downstream of $\mathrm{p} 38 \gamma$ and $\mathrm{p} 38 \delta$ to promote degradation of the stemness proteins and to suppress stemness in NSCLC cells. It has been reported that Hsp27 promotes the ubiquitylation and proteasomal degradation of multiple proteins in response to stresses that activate the p38 pathway [31-33]. While the exact mechanism for the role of Hsp27 in this process is currently not fully understood, it appears that Hsp27 participates in a general proteasomal degradation machinery that is responsible for the degradation of at least a subset of proteins, that Hsp27 directly binds to the proteins targeted for degradation, polyubiquitin chain and the $26 \mathrm{~S}$ proteasome in vitro and in vivo, and that interaction of Hsp27 with the 26S proteasome is required for activation of the proteasome and the degradation of the protein target [31]. We therefore reason that the stemness proteins including SOX2, Oct4, Nanog, Klf4 and c-Myc belong to this subset of proteins that are subjected to regulation by this proteasomal degradation machinery containing Hsp27. Supporting this notion, Hsp 27 interacts with the stemness proteins, and these interactions were enhanced by the phosphomimetic mutations at the MK2 phosphorylation sites of Hsp27, suggesting that $\mathrm{p} 38 / \mathrm{MK} 2$-mediated phosphorylation of Hsp27 leads to increased binding of Hsp27 to the stemness proteins, thus promoting the proteasomal degradation of these proteins.

Our data indicate that among the 4 p38 isoforms, $\mathrm{p} 38 \gamma$ and $\mathrm{p} 38 \delta$ are responsible for promoting the degradation of stemness proteins and suppressing the stemness in NSCLC cells, while p38 $\alpha$ and p38 $\beta$ appear to be dispensable for this function. Consistent with the lack of involvement of $\mathrm{p} 38 \alpha$ and $\mathrm{p} 38 \beta$ in regulation of stemness, treatment of NSCLC cells with SB203580, a compound that mainly inhibits $\mathrm{p} 38 \alpha$ and $\mathrm{p} 38 \beta$ but only weakly $\mathrm{p} 38 \gamma$ and $\mathrm{p} 38 \delta$, modestly increased the expression of SOX2 but not that of Oct4 and other stemness proteins (Supplementary Figure 7A), and failed to increase the percentage of the side population or the ability to form spheres (Supplementary Figure 7B, 7C). The mechanistic basis for the differential roles of the p38 isoforms in stemness regulation is currently unclear.

Cancer stem cells (CSCs) are a major source for tumor initiation, tumor relapse, and drug resistance, and play an important role in cancer development [4]. Results presented in the study have revealed a novel signaling pathway that regulates the stemness properties of lung cancer cells. Our data indicate that inactivation of $\mathrm{p} 38$, which occurs frequently in lung cancer tissues, can lead to increased stemness in lung cancer cells. This finding has thus provided a new mechanism underlying the acquisition and maintenance of CSCs during lung cancer development and has identified a new target for cancer therapies aimed at eliminating CSCs. It will be interesting to determine whether inactivation of p38 also contributes to the development of CSCs in other types of cancers.

\section{MATERIALS AND METHODS}

\section{Cell culture}

A549, H1299 and H460 cell lines were maintained in RPMI-1640 (BioInd) supplemented with 10\% fetal calf serum (BioInd), 1\% antibiotics (penicillin and streptomycin). All these three cell lines are NSCLC cells. A549 is an epithelial cell type initiated through explant culture of lung carcinomatous tissue from a 58-year-old Caucasian male, and is a hypotriploid human cell line with the modal chromosome number of 66 , occurring in $24 \%$ of cells. H460 is an epithelial-like large cell lung cancer cell line and a hypotriploid human cell line with the modal chromosome number of 57 although cells with 58 chromosomes occurred with a comparable frequency. It was derived from the pleural fluid of a patient with large 
cell cancer of the lung. H1299 is a non-small cell lung cancer cell line established from a lymph node metastasis of the lung from a patient.

If necessary, $10 \mu \mathrm{M}$ of $\mathrm{SB} 203580$ was added to medium to inhibit p38. A549-MKK3E/6E, H460MKK3E/6E，H460-MKK3A/6A， H1299-MKK3A/6A, A549 active mutant cell lines (BP, p38 $\alpha \mathrm{WT}, \mathrm{p} 38 \alpha \mathrm{D} 176 \mathrm{~A}$, p38 $\beta W T, p 38 \beta D 176 A, p 38 \gamma W T, p 38 \gamma D 179 A, p 38 \delta W T$,

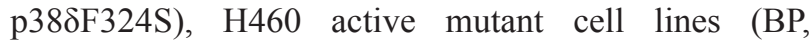
p38 $\alpha \mathrm{WT}$, p38 $\alpha \mathrm{D} 176 \mathrm{~A}, \mathrm{p} 38 \beta \mathrm{WT}, \mathrm{p} 38 \beta \mathrm{D} 176 \mathrm{~A}, \mathrm{p} 38 \gamma \mathrm{WT}$,

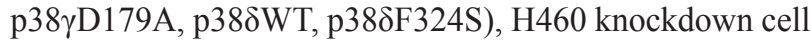

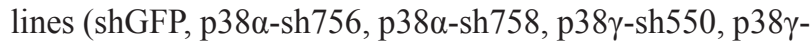

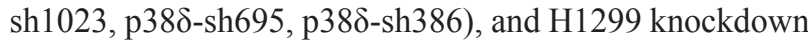

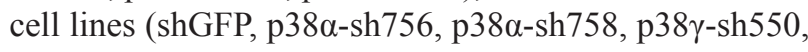

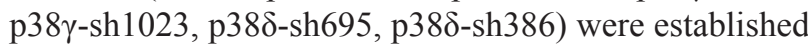
by infecting the lung cancer cell lines with corresponding retroviral constructs we reported previously $[25,26,52]$

\section{Plasmids and lentivirus-based gene transduction}

Oligos encoding shRNAs for p38 $\beta$ (p38 $\beta$-sh751: 5'-AAAAGCTGAAGCGCATCATGGAATTGGATCCA ATTCCATGATGCGCTTCAGC-3' and p38 $\beta$-sh652: 5'-AAAAGCATTACAACCAAACAGTGTTGGATCCA ACACTGTTTGGTTGTAATGC-3'), shRNAs for PRAK (shPK-1: 5'-GCTGGAATTAGTGGTCCAG-3' and shPK2: 5'-GTGTCTATATCCACGACCA-3'), and shRNAs for MK2 (shMK2-1: 5'-GGAGAACTCTTTAGCCGA ATC-3' and shMK2-2: 5'-GCCATCCAGTATCTGCATT CA-3') were designed, synthesized, and inserted into pLVH1-EF1 $\alpha$-puro (Biosettia), according to manufacturer's protocol. Human HA-SOX2 plasmid was amplified by PCR using TransStart FastPfu DNA Polymerase kit (TransGen Biotech, AP221), and inserted into pLV-EF1 $\alpha$ MCS-IRES-Bsd (Biosettia). The Hsp27 mutant plasmids were constructed using the method described by Anna M. Knapinska [33] and inserted into pLV-EF1 $\alpha$-MCS-IRESBsd (Biosettia).

All mutants were verified by DNA sequencing. Recombinant lentiviruses were packaged and transduced into cells as described previously [53].

\section{Protein extraction and western blotting}

Protein extraction and western blotting methods were performed as described previously [53]. The antibodies used in this study including anti- $\beta$-actin (Santa cruz; sc-47778), anti-p38 (abcam; ab32142), antiphopho-p38 MAPK(Cell signaling Technology; \#9215), anti-SOX2 (Santa cruz; sc-20088), anti-Oct4 (abcam; ab19857), anti-HA (Cell signaling Technology, \#3724), anti-c-Myc (Cell signaling Technology; \#13987), antiNanog (abcam; ab80892), anti-Klf4 (Cell signaling Technology, \#4038), anti-ERK (Beijing Zhongshan Golden Bridge Biotechnology Co Ltd, ZS94), anti-Ub (Santa cruz, sc-8017), anti-phospho-ATF2 (Cell signaling Technology, \#9221). The anti-p38 $\alpha$, anti-p38 $\beta$, anti- p38 $\gamma$, anti-p38 , anti-MKK3, anti-MKK6 antibodies were previously described by Kwong [26]. The p38 inhibitor SB203580 was from Sigma (s8307). For the protein stability assay of the stemness protein, cells were treated with cycloheximide (Cayman chemical, 14126) at $20 \mu \mathrm{g} / \mathrm{ml}$ concentration for $0 \mathrm{~h}, 1 \mathrm{~h}, 2 \mathrm{~h}, 6 \mathrm{~h}, 9 \mathrm{~h}, 15 \mathrm{~h}$ before lysates were collected. For the ubiquitylation assay, cells were treated with MG132 (Sigma, c2211) at $10 \mu \mathrm{M}$ concentration for $6 \mathrm{~h}$ before lysates were collected.

\section{RNA isolation, reverse transcription and qRT- PCR analysis}

RNA isolation, reverse transcription and qRT-PCR analysis were performed as described previously [54]. Primers used for PCR amplification are the following: SOX2-F: 5'-GCCTGGGCGCCGAGTGGA-3'. SOX2-R: 5'-GGGCGAGCCGTTCATGTAGGTCTG-3'. Oct4-F: 5'-GC TCGAGAAGGATGTGGTCC-3'. Oct4-R: 5'-CGTTGT GCATAGTCGCTGCT-3'. Nanog-F: 5'-TCTGGACACT GGCTGAATCCT-3'. Nanog-R: 5'-CGCTGATTAGGC TCCAACCAT-3'. Klf4-F: 5'-AGAGGAGCCCAAGCC AAAG-3'. Klf4-R: 5'-CGTCCCAGTCACAGTGGTAA GGT-3'. c-Myc-F： 5'-GTCAAGAGGCGAACACACA AC-3'. c-Myc-R: 5'-TTGGACGGACAGGATGTATGC-3'.

\section{Immunoprecipitation and SOX2 ubiquitylation assay}

Cell lysates from A549-BP, A549-BP-HA-SOX2, A549-MKK3E-HA-SOX2, H1299-BH, H1299-BH-HASOX2, and H1299-MKK6A-HA-SOX2 cells that had been treated with MG132 $(10 \mu \mathrm{M})$ for $6 \mathrm{~h}$ or left untreated were prepared as described previously [53], sonicated five times for 2 seconds each, and then cleared by centrifugation at $13,000 \mathrm{rpm}, 4^{\circ} \mathrm{C}$ for 15 minutes. Protein concentrations were determined by BCA protein assay (Pierce, Thermo Scientific). Typically $9 \mu \mathrm{g}$ of protein lysates was subjected to direct Western blot analysis as input. For immunoprecipitation, $500 \mu \mathrm{g}$ of cell lysates were mixed with $5 \mu \mathrm{l}$ of anti-HA-antibody (CST, \#3724) in $500 \mu \mathrm{l}$ of total volume, incubated at $4^{\circ} \mathrm{C}$ for overnight with rotation, and then incubated with $40 \mu \mathrm{l}$ bead volume of pre-washed protein G-agarose beads (CWBIO, CW0012A) for additional 2 hours. The beads were spun down at $4,000 \mathrm{rpm}, 4^{\circ} \mathrm{C}$ for 1 minute and washed twice with lysis buffer. The beads were resuspended in $80 \mu \mathrm{l}$ of $2 \mathrm{X}$ Laemmli buffer and heated at $100^{\circ} \mathrm{C} .10 \mu \mathrm{l}$ of the beads supernatant was separated on SDS-PAGE gel for Western blot analysis. To detect SOX2 ubiquitylation, the ubiquitylated protein was detected by Western blot using an anti-ubiquitin antibody (sc-8017, Santa Cruz).

\section{Immunoprecipitation for Hsp27}

For co-immunoprecipitation of Hsp27, total proteins from A549-MCS, A549-Hsp27-WT and A549-Hsp27- 
TriD cells were extracted, and protein concentrations were determined by BCA protein assay. Typically $10 \mu \mathrm{g}$ of protein lysates was subjected to direct Western blot analysis as input. For immunoprecipitation, $500 \mu \mathrm{g}$ of cell lysates were mixed with $5 \mu$ l of anti-Hsp27-antibody (Santa, sc13132) in $500 \mu \mathrm{l}$ of total volume, incubated at $4^{\circ} \mathrm{C}$ for overnight with rotation, and then incubated with $40 \mu \mathrm{l}$ bead volume of pre-washed protein G-agarose beads (CWBIO, CW0012A) for additional 4 hours. The beads were spun down at $4,000 \mathrm{rpm}, 4^{\circ} \mathrm{C}$ for 1 minute and washed twice with lysis buffer. The beads were resuspended in $40 \mu \mathrm{l}$ of $2 \mathrm{X}$ Laemmli buffer and heated at $100^{\circ} \mathrm{C} .5 \mu \mathrm{l}$ of the beads supernatant was separated on SDS-PAGE gel for Western blot analysis to detect the Hsp27, SOX2, Oct4, Nanog, Klf4 and c-Myc.

\section{Immunoprecipitation-coupled protein kinase assays for p38 (HA)}

Cells were lysed in lysis buffer containing 50 mM HEPES, pH 7.5, 2.5 mM EGTA, 1 mM EDTA, $1 \%$ Triton X-100, $150 \mathrm{mM} \mathrm{NaCl}, 10 \%$ glycerol, $1 \mathrm{mM}$ PMSF, $50 \mathrm{mM} \mathrm{NaF}, 1 \mathrm{mM}$ sodium vanadate, $1 \mathrm{mM}$ betaglycerophosphate, $1 \mathrm{mM}$ DTT, and Complete protease inhibitors. Cells were scraped off the plate, transferred to microcentrifuge tubes, and incubated on ice for 30 minutes. Cell lysates were sonicated five times for 2 seconds each, and then cleared by centrifugation at $13,000 \mathrm{rpm}, 4^{\circ} \mathrm{C}$ for 15 minutes. Protein concentrations were determined by BCA protein assay (Pierce). $500 \mu \mathrm{g}$ of lysate were incubated with $5 \mu \mathrm{g}$ of anti-HA antibody (CST, \#3724) at $4^{\circ} \mathrm{C}$ overnight, followed by incubation with $50 \mu \mathrm{l}$ of Protein $\mathrm{G}$ agarose (CWBIO, CW0012A) at $4^{\circ} \mathrm{C}$ for $2 \mathrm{~h}$. The beads were washed with lysis buffer and kinase buffer (50 mM HEPES, pH 7.5, 0.5 mM EGTA, $10 \mathrm{mM} \mathrm{MgCl}_{2}$, $0.1 \mathrm{mM}$ PMSF, $1 \mathrm{mM} \mathrm{NaF}, 0.1 \mathrm{mM}$ sodium vanadate, $0.1 \mathrm{mM}$ beta-glycerophosphate, and 1mM DTT). Kinase reactions were performed in $20 \mu$ of kinase buffer with $20 \mu \mathrm{M}$ of ATP (CST, \#9804) and $10 \mu \mathrm{g}$ of recombinant ATF2(CST, \#9224) as substrate at $30^{\circ} \mathrm{C}$ for $45 \mathrm{~min}$ Reactions were stopped by addition of $7 \mu$ of $4 \times$ Laemmli buffer, heated at $95^{\circ} \mathrm{C}$ for $10 \mathrm{~min}$, and separated by SDSPAGE and transferred to nitrocellulose membrane. The membrane was incubated with anti-p-ATF2 antibody (CST, \#9221) to detect the level of phosphorylation of ATF2.

\section{Side population assay}

Lung cancer cell lines cultured in 6-well plates were live stained with $5 \mu \mathrm{g} / \mathrm{ml}$ Hoechst33342 in $1 \mathrm{ml}$ of buffer (2\% FBS in PBS) at $37 \mathrm{C}$ with $5 \% \mathrm{CO}_{2}$ for $1 \mathrm{~h}$. The ABCG2 blocker FTC (for A549, $10 \mathrm{mM}$, Sigma F9054) or resperin (for H460 and H1299, 5 mM, Sigma R0875 was added to the blocker control well for each condition $30 \mathrm{~min}$ before addition of Hoechst 33342 [55-57]. Subsequently, the supernatant was removed, and the cells were scraped in RPMI-1640 and transferred to tubes. Cells were collected by centrifugation at $1,000 \mathrm{rpm}, 4^{\circ} \mathrm{C}$ for 5 minutes, and resuspended in $1 \mathrm{ml}$ of cold buffer ( $2 \%$ FBS in PBS). Propidium iodide (PI) was added to the buffer at the $1 \mu \mathrm{g} / \mathrm{ml}$ final concentration. Flow cytometric analysis was performed on BD FACS (BD Biosciences). The Hoechst 33342 dye was excited at 355 $\mathrm{nm}$, and fluorescence was measured with both a $670 / 50$ filter (Hoechst Red) and a 450/50 filter (Hoechst Blue). The side population was gated for each condition based on the population of cells that disappeared in the blocker control for this condition.

\section{Sphere formation assay}

H460, H1299 and A549 cells were seeded in lowadherent 24-well culture plates (Corning, NY, USA) at $2 \times 10^{3}$ cells per well, and incubated under serum-free condition in RPMI1640 (BioInd) containing $20 \mu \mathrm{l} / \mathrm{ml}$ of B27 (Invitrogen, CA, USA), $20 \mathrm{ng} / \mathrm{ml}$ of epidermal growth factor (EGF) (Invitrogen, Carlsbad, CA, USA), $20 \mathrm{ng} / \mathrm{ml}$ of basic fibroblast growth factor (bFGF) (Invitrogen, Carlsbad, CA, USA) and $1 \%$ of penicillin-streptomycin (HyClone, Logan City, Utah, USA). After incubation at $37^{\circ} \mathrm{C}$ in a $5 \%$ $\mathrm{CO} 2$ incubator for 5-14 days, pictures were taken under a microscope and the number of spheres was counted in three separate $40 \times$ fields.

\section{Tumor cell xenograft mouse models}

Male NOD-Scid mice (4-6 week old) were used to perform this experiment. To assess the tumor-initiating ability in vivo, varying numbers $\left(1 \times 10^{6}, 5 \times 10^{5}, 1 \times 10^{5}\right.$,

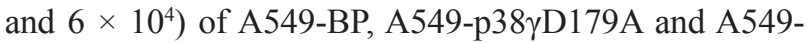
p38 8 F324S cells at early passage were suspended in $200 \mu \mathrm{l}$ of $50 \%$ (V/V) Matrigel in RPMI1640, and subcutaneously (s.c.) injected into both flanks of NOD-Scid mice. The length and width of tumors were measured, and tumor volume was calculated (Tumor volumes $=$ length $\times$ width $^{2} / 2$ ). Mice were sacrificed on the 24 th day after injection. 4 mice were used for each experimental group. The animal use complied with Nankai University Animal Welfare Guidelines.

\section{Immunohistochemistry for tissue array}

Serial sections of human lung tumor tissue array containing 153 intact NSCLC tumor tissues (79 squamous cell carcinoma and 74 adenocarcinoma) and 31 intact normal lung tissues/normal adjacent lung tissue (NAT) (18 normal lung tissue and 13 NAT) were purchased from Alenabio (LC1921a). Immunohistochemical analysis was performed following previously published methods [54], using 1:200 dilution of the anti-SOX2 antibody (CST, \#3579) and 1:100 dilution of the anti-p-p38 antibody (CST, \#4511). The images were recorded by an Olympus 
BX51 Epi-fluorescent microscope under a 20X objective (Olympus Co., Tokyo, Japan). For quantification, area of positive staining for SOX2 and p-p38 in normal and tumor tissues was calculated by multiplying staining area (scored as $1,2,3$, and 4, 1: 0-25\%, 2: 25\%-50\%, 3: 50\%-75\%, 4: $75 \%-100 \%$, of positive tissue area) with staining intensity (scored as 1, 2, 3, and 4 based on color). Student's $t$-test was performed for comparison of data.

\section{Statistical analyses}

All values are expressed as mean \pm standard deviation. Independent $t$ test was performed for comparison of data of independent samples. A $P$ value $<0.05$ was considered significant.

\section{ACKNOWLEDGMENTS AND FUNDING}

This project is supported by the National Basic Research Program (973) of China (No. 2013CB967202), the National Natural Science Foundation of China (No. 81273331, No. 31428013, and No. 81470354), and National Institute of Health of USA (R01CA131231 and R01CA172115).

\section{CONFLICTS OF INTEREST}

None.

\section{REFERENCES}

1. Parkin DM, Bray F, Ferlay J, Pisani P. Global cancer statistics, 2002. CA Cancer J Clin. 2005; 55:74-108.

2. Liu CL, Chen SF, Wu MZ, Jao SW, Lin YS, Yang CY, Lee TY, Wen LW, Lan GL, Nieh S. The molecular and clinical verification of therapeutic resistance via the p38 MAPK-Hsp27 axis in lung cancer. Oncotarget. 2016; 7:14279-14290. doi: 10.18632/oncotarget.7306.

3. Molina JR, Yang P, Cassivi SD, Schild SE, Adjei AA. Nonsmall cell lung cancer: epidemiology, risk factors, treatment, and survivorship. Mayo Clinic proceedings. 2008; 83:584-594.

4. Lathia JD, Heddleston JM, Venere M, Rich JN. Deadly teamwork: neural cancer stem cells and the tumor microenvironment. Cell stem cell. 2011; 8:482-485.

5. Wang YD, Cai N, Wu XL, Cao HZ, Xie LL, Zheng PS. OCT4 promotes tumorigenesis and inhibits apoptosis of cervical cancer cells by miR-125b/BAK1 pathway. Cell death \& disease. 2013; 4:e760.

6. Ji J, Zheng PS. Expression of Sox2 in human cervical carcinogenesis. Human pathology. 2010; 41:1438-1447.

7. Wen J, Park JY, Park KH, Chung HW, Bang S, Park SW, Song SY. Oct4 and Nanog expression is associated with early stages of pancreatic carcinogenesis. Pancreas. 2010; 39:622-626.
8. Wei D, Kanai M, Jia Z, Le X, Xie K. Kruppel-like factor 4 induces p27Kip1 expression in and suppresses the growth and metastasis of human pancreatic cancer cells. Cancer research. 2008; 68:4631-4639.

9. Abdelalim EM, Emara MM, Kolatkar PR. The SOX transcription factors as key players in pluripotent stem cells. Stem cells and development. 2014; 23:2687-2699.

10. Gangemi RM, Griffero F, Marubbi D, Perera M, Capra MC, Malatesta P, Ravetti GL, Zona GL, Daga A, Corte G. SOX2 silencing in glioblastoma tumor-initiating cells causes stop of proliferation and loss of tumorigenicity. Stem cells. 2009; 27:40-48.

11. Basu-Roy U, Seo E, Ramanathapuram L, Rapp TB, Perry JA, Orkin SH, Mansukhani A, Basilico C. Sox2 maintains self renewal of tumor-initiating cells in osteosarcomas. Oncogene. 2012; 31:2270-2282.

12. Chou YT, Lee CC, Hsiao SH, Lin SE, Lin SC, Chung CH, Chung $\mathrm{CH}$, Kao YR, Wang YH, Chen CT, Wei YH, $\mathrm{Wu} \mathrm{CW}$. The emerging role of SOX2 in cell proliferation and survival and its crosstalk with oncogenic signaling in lung cancer. Stem cells. 2013; 31:2607-2619.

13. Leis O, Eguiara A, Lopez-Arribillaga E, Alberdi MJ, Hernandez-Garcia S, Elorriaga K, Pandiella A, Rezola R, Martin AG. Sox 2 expression in breast tumours and activation in breast cancer stem cells. Oncogene. 2012; 31:1354-1365.

14. Bareiss PM, Paczulla A, Wang H, Schairer R, Wiehr S, Kohlhofer U, Rothfuss OC, Fischer A, Perner S, Staebler A, Wallwiener D, Fend F, Fehm T, et al. SOX2 expression associates with stem cell state in human ovarian carcinoma. Cancer research. 2013; 73:5544-5555.

15. Santini R, Pietrobono S, Pandolfi S, Montagnani V, D'Amico M, Penachioni JY, Vinci MC, Borgognoni L, Stecca B. SOX2 regulates self-renewal and tumorigenicity of human melanoma-initiating cells. Oncogene. 2014; 33:4697-4708.

16. Cuadrado A, Nebreda AR. Mechanisms and functions of p38 MAPK signalling. The Biochemical journal. 2010; 429:403-417.

17. Xu Y, Li N, Xiang R, Sun P. Emerging roles of the p 38 MAPK, $\mathrm{PI} 3 \mathrm{~K} / \mathrm{AKT} / \mathrm{mTOR}$ pathways in oncogene-induced senescence. Trends in biochemical sciences. 2014; 39:268-276.

18. del Barco Barrantes I, Nebreda AR. Roles of p38 MAPKs in invasion and metastasis. Biochemical Society transactions. 2012; 40:79-84.

19. Loesch M, Chen G. The p38 MAPK stress pathway as a tumor suppressor or more? Frontiers in bioscience. 2008; 13:3581-3593.

20. Wagner EF, Nebreda ÁR. Signal integration by JNK and p38 MAPK pathways in cancer development. Nature Reviews Cancer. 2009; 9:537-549.

21. Cuenda A, Rouse J, Doza YN, Meier R, Cohen P, Gallagher TF, Young PR, Lee JC. SB 203580 is a specific inhibitor of a MAP kinase homologue which is stimulated by cellular stresses and interleukin-1. FEBS letters. 1995; 364:229-233. 
22. Risco A, Cuenda A. New Insights into the p38gamma and p38delta MAPK Pathways. Journal of signal transduction. 2012; 2012:520289.

23. Cerezo-Guisado MI, del Reino P, Remy G, Kuma Y, Arthur JS, Gallego-Ortega D, Cuenda A. Evidence of p38gamma and p38delta involvement in cell transformation processes. Carcinogenesis. 2011; 32:1093-1099.

24. Gao L, Smit MA, van den Oord JJ, Goeman JJ, Verdegaal EM, van der Burg SH, Stas M, Beck S, Gruis NA, Tensen CP, Willemze R, Peeper DS, van Doorn R. Genomewide promoter methylation analysis identifies epigenetic silencing of MAPK13 in primary cutaneous melanoma. Pigment cell \& melanoma research. 2013; 26:542-554.

25. Kwong J, Hong L, Liao R, Deng Q, Han J, Sun P. p38alpha and p38gamma mediate oncogenic ras-induced senescence through differential mechanisms. The Journal of biological chemistry. 2009; 284:11237-11246.

26. Kwong J, Chen M, Lv D, Luo N, Su W, Xiang R, Sun P. Induction of p38delta expression plays an essential role in oncogenic ras-induced senescence. Molecular and cellular biology. 2013; 33:3780-3794.

27. Lianos GD, Alexiou GA, Mangano A, Mangano A, Rausei S, Boni L, Dionigi G, Roukos DH. The role of heat shock proteins in cancer. Cancer letters. 2015; 360:114-118.

28. Kim KK, Kim R, Kim SH. Crystal structure of a small heatshock protein. Nature. 1998; 394:595-599.

29. Mizutani H, Okano T, Minegishi Y, Matsuda K, Sudoh J, Kitamura K, Noro R, Soeno C, Yoshimura A, Seike M, Gemma A. HSP27 modulates epithelial to mesenchymal transition of lung cancer cells in a Smad-independent manner. Oncology letters. 2010; 1:1011-1016.

30. Tweedle EM, Khattak I, Ang CW, Nedjadi T, Jenkins R, Park BK, Kalirai H, Dodson A, Azadeh B, Terlizzo M, Grabsch H, Mueller W, Myint S, et al. Low molecular weight heat shock protein HSP27 is a prognostic indicator in rectal cancer but not colon cancer. Gut. 2010; 59:1501-1510.

31. Parcellier A, Schmitt E, Gurbuxani S, Seigneurin-Berny D, Pance A, Chantome A, Plenchette S, Khochbin S, Solary E, Garrido C. HSP27 is a ubiquitin-binding protein involved in I-kappaBalpha proteasomal degradation. Molecular and cellular biology. 2003; 23:5790-5802.

32. Parcellier A, Brunet M, Schmitt E, Col E, Didelot C, Hammann A, Nakayama K, Nakayama KI, Khochbin S, Solary E, Garrido C. HSP27 favors ubiquitination and proteasomal degradation of p27Kip1 and helps S-phase reentry in stressed cells. FASEB journal. 2006; 20:1179-1181.

33. Knapinska AM, Gratacos FM, Krause CD, Hernandez K, Jensen AG, Bradley JJ, Wu X, Pestka S, Brewer G. Chaperone Hsp27 modulates AUF1 proteolysis and AUrich element-mediated mRNA degradation. Molecular and cellular biology. 2011; 31:1419-1431.

34. Larsen JK, Yamboliev IA, Weber LA, Gerthoffer WT. Phosphorylation of the $27-\mathrm{kDa}$ heat shock protein via $\mathrm{p} 38$
MAP kinase and MAPKAP kinase in smooth muscle. The American journal of physiology. 1997; 273:L930-940.

35. New L, Jiang Y, Zhao M, Liu K, Zhu W, Flood LJ, Kato Y, Parry GC, Han J. PRAK, a novel protein kinase regulated by the p38 MAP kinase. The EMBO journal. 1998; 17:3372-3384.

36. Sun P, Yoshizuka N, New L, Moser BA, Li Y, Liao R, Xie C, Chen J, Deng Q, Yamout M, Dong MQ, Frangou CG, Yates JR 3rd, et al. PRAK is essential for ras-induced senescence and tumor suppression. Cell. 2007; 128:295-308.

37. Ventura JJ, Tenbaum S, Perdiguero E, Huth M, Guerra C, Barbacid M, Pasparakis M, Nebreda AR. p38alpha MAP kinase is essential in lung stem and progenitor cell proliferation and differentiation. Nature genetics. 2007; 39:750-758.

38. Hui L, Bakiri L, Mairhorfer A, Schweifer N, Haslinger C, Kenner L, Komnenovic V, Scheuch H, Beug H, Wagner EF. p38alpha suppresses normal and cancer cell proliferation by antagonizing the JNK-c-Jun pathway. Nature genetics. 2007; 39:741-749.

39. Goodell MA, Brose K, Paradis G, Conner AS, Mulligan RC. Isolation and functional properties of murine hematopoietic stem cells that are replicating in vivo. The Journal of experimental medicine. 1996; 183:1797-1806.

40. Zhou S, Schuetz JD, Bunting KD, Colapietro AM, Sampath J, Morris JJ, Lagutina I, Grosveld GC, Osawa M, Nakauchi H, Sorrentino BP. The ABC transporter Bcrp1/ ABCG2 is expressed in a wide variety of stem cells and is a molecular determinant of the side-population phenotype. Nature medicine. 2001; 7:1028-1034.

41. Abbott BL, Colapietro AM, Barnes Y, Marini F, Andreeff M, Sorrentino BP. Low levels of ABCG2 expression in adult AML blast samples. Blood. 2002; 100:4594-4601.

42. Challen GA, Little MH. A side order of stem cells: the SP phenotype. Stem cells. 2006; 24:3-12.

43. Tsuchiya A, Heike T, Baba S, Fujino H, Umeda K, Matsuda Y, Nomoto M, Ichida T, Aoyagi Y, Nakahata T. Long-term culture of postnatal mouse hepatic stem/ progenitor cells and their relative developmental hierarchy. Stem cells. 2007; 25:895-902.

44. Yu JB, Jiang H, Zhan RY. Aberrant Notch signaling in glioblastoma stem cells contributes to tumor recurrence and invasion. Molecular medicine reports. 2016; 14:1263-1268.

45. O'Callaghan C, Fanning LJ, Barry OP. p38delta MAPK: Emerging Roles of a Neglected Isoform. International journal of cell biology. 2014; 2014:272689.

46. Wen HC, Avivar-Valderas A, Sosa MS, Girnius N, Farias EF, Davis RJ, Aguirre-Ghiso JA. p38alpha Signaling Induces Anoikis and Lumen Formation During Mammary Morphogenesis. Science signaling. 2011; 4:ra34.

47. Koul HK, Pal M, Koul S. Role of p38 MAP Kinase Signal Transduction in Solid Tumors. Genes Cancer. 2013; 4:342-59. doi: 10.1177/1947601913507951. 
48. Yoshizuka N, Chen RM, Xu Z, Liao R, Hong L, Hu WY, Yu G, Han J, Chen L, Sun P. A novel function of p38regulated/activated kinase in endothelial cell migration and tumor angiogenesis. Molecular and cellular biology. 2012; 32:606-618.

49. Bulavin DV, Demidov ON, Saito S, Kauraniemi $P$, Phillips C, Amundson SA, Ambrosino C, Sauter G, Nebreda AR, Anderson CW, Kallioniemi A, Fornace AJ, Jr. and Appella E. Amplification of PPM1D in human tumors abrogates p53 tumor-suppressor activity. Nature genetics. 2002; 31:210-215.

50. Rauta J, Alarmo EL, Kauraniemi P, Karhu R, Kuukasjarvi T, Kallioniemi A. The serine-threonine protein phosphatase PPM1D is frequently activated through amplification in aggressive primary breast tumours. Breast cancer research and treatment. 2006; 95:257-263.

51. Dolado I, Swat A, Ajenjo N, De Vita G, Cuadrado A, Nebreda AR. p38alpha MAP kinase as a sensor of reactive oxygen species in tumorigenesis. Cancer cell. 2007; 11:191-205.

52. Xu Y, Liao R, Li N, Xiang R, Sun P. Phosphorylation of Tip60 by $\mathrm{p} 38$ alpha regulates $\mathrm{p} 53$-mediated PUMA induction and apoptosis in response to DNA damage. Oncotarget. 2014; 5:12555-12572. doi: 10.18632/oncotarget.2717.
53. Chang A, Chen Y, Shen W, Gao R, Zhou W, Yang S, Liu Y, Luo Y, Chuang TH, Sun P, Liu C, Xiang R. Ifit1 Protects Against Lipopolysaccharide and D-galactosamine-Induced Fatal Hepatitis by Inhibiting Activation of the JNK Pathway. The Journal of infectious diseases. 2015; 212:1509-1520.

54. Shen W, Chang A, Wang J, Zhou W, Gao R, Li J, Xu Y, Luo X, Xiang R, Luo N, Stupack DG. TIFA, an inflammatory signaling adaptor, is tumor suppressive for liver cancer. Oncogenesis. 2015; 4:e173.

55. Cao B, Jia J, Ma L, Di L, Song G, Yuan Y, Ma B, Zhu Y, Yu J, Wang X, Zhou X, Lyerly HK, Ren J. Recombinant human endostatin could eliminate the pro-angiogenesis priority of SP cells sorted from non-small cell lung cancer cells. Clinical \& translational oncology. 2012; 14:575-585.

56. Ho MM, Ng AV, Lam S, Hung JY. Side population in human lung cancer cell lines and tumors is enriched with stem-like cancer cells. Cancer research. 2007; 67:4827-4833.

57. Singh S, Bora-Singhal N, Kroeger J, Laklai H, Chellappan SP. betaArrestin-1 and Mcl-1 modulate selfrenewal growth of cancer stem-like side-population cells in non-small cell lung cancer. PloS one. 2013; 8:e55982. 